\title{
Enriched environment and social isolation affect cognition ability via altering excitatory and inhibitory synaptic density in mice hippocampus
}

Hui Wang

Nankai University College of Life Sciences

Xiaxia Xu

Nankai University College of Life Sciences

Jing Gao

Nankai University School of Medicine

Tao Zhang ( $\square$ zhangtao@nankai.edu.cn )

Nankai University https://orcid.org/0000-0002-5743-4657

\section{Research}

Keywords: synaptic plasticity, neural oscillation, synaptic density, enriched environment, social isolation

Posted Date: February 13th, 2020

DOI: https://doi.org/10.21203/rs.2.23450/v1

License: (a) (i) This work is licensed under a Creative Commons Attribution 4.0 International License.

Read Full License

Version of Record: A version of this preprint was published at Neurochemical Research on August 3rd, 2020. See the published version at https://doi.org/10.1007/s11064-020-03102-2. 

(1)

\title{
Enriched environment and social isolation affect cognition
}

\section{ability via altering excitatory and inhibitory synaptic density} in mice hippocampus

\author{
Hui Wang ${ }^{1}$, Xiaxia $\mathrm{Xu}^{1}$, Jing $\mathrm{Gao}^{2}$,Tao Zhang ${ }^{1 *}$ \\ ${ }^{1}$ College of Life Sciences and Key Laboratory of Bioactive Materials Ministry of Education, \\ Nankai University, 300071 Tianjin, PR China
}

${ }^{2}$ School of Medicine, Nankai University, Tianjin 300071, PR China

Running title: Housing environment change E/I synaptic density

* Corresponding author: Tao Zhang

Tel.: +8622 23500237

E-mail address: zhangtao@nankai.edu.cn 


\begin{tabular}{|c|c|}
\hline AMPA & a-amino-3-hydroxy-5-methyl-4-isoxazole propionic acid \\
\hline DEP & depotentiation \\
\hline DG & dentate gyrus \\
\hline $\mathrm{EE}$ & enriched environment \\
\hline $\mathrm{E} / \mathrm{I}$ & excitatory/inhibitory \\
\hline fEPSP & field excitatory postsynaptic potential \\
\hline HG & high gamma \\
\hline HRP & horseradish peroxidase \\
\hline IT & initial training \\
\hline LFPs & local field potentials \\
\hline LFS & low-frequency afferent stimulation \\
\hline LG & low gamma \\
\hline LTD & long-term depression \\
\hline LTP & long term potentiation \\
\hline MWM & Morris water maze \\
\hline MI & modulation index \\
\hline NMDAR & N-methyl-D-aspartic acid receptor \\
\hline PAC & phase-amplitude coupling \\
\hline PLV & phase locking value \\
\hline PP & perforant pathway \\
\hline PPC & phase- phase coupling \\
\hline PSD & power spectrum density \\
\hline PSD-95 & postsynaptic density protein 95 \\
\hline PVDF & poly vinylidene fluoride \\
\hline RET & reversal exploring test \\
\hline RI & recognition index \\
\hline RT & reversal training \\
\hline SET & space exploring test \\
\hline
\end{tabular}


SI

SYP

TBS social isolation

synaptophysin

theta burst stimulation

19

20 


\section{Abstract}

Background: The purpose of the study was to examine whether the underlying mechanism of the alteration of cognitive ability and synaptic plasticity induced by the housing environment is associated with the balance of excitatory/inhibitory synaptic density. Enriched environment (EE) and social isolation (SI) are two different housing environment, and one is to give multiple sensory environments, the other is to give monotonous and lonely environment.

Results: Male four-week-old C57 mice were divided into three groups: CON, EE and SI. They were housed in the different cage for 3 months. Morris water maze (MWM) and novel object recognition were performed. Long term potentiation (LTP), depotentiation (DEP) and Local field potential (LFPs) were recorded in the hippocampal perforant pathway (PP) and dentate gyrus (DG). The data showed that EE enhanced the ability of spatial learning, reversal learning and memory as well as LTP/DEP in the hippocampal DG region. Meanwhile, SI reduced those abilities and the level of LTP/DEP. Moreover, there were higher couplings of both phase-amplitude and phase-phase in the EE group, and lower couplings of them in the SI group compared to that in the $\mathrm{CON}$ group. Western blot analysis showed that $\mathrm{EE}$ significantly enhanced the level of PSD-95, NR2B; however, SI reduced them but enhanced level of GABAAR.

Conclusion: These date suggests that the cognitive functions, synaptic plasticity and neural oscillatory patterns were significantly impacted by housing environment via possibly changing the balance of excitatory and inhibitory synaptic density.

Keywords: synaptic plasticity; neural oscillation; synaptic density; enriched environment; social isolation 


\section{Introduction}

Previous studies have shown that the housing environment can impact human being and animal behaviors and physiological functions. Enriched environment (EE) stimulation is a noninvasive strategy to enhance neuronal plasticity in vivo. Through multiple sensory stimulation (e.g. toys, wheels, bells and tunnels), EE promotes plasticity of experiment animal neuronal circuits, enhances learning and memory ability [1]. In the behavioral experiment, EE could enhance cognitive ability and decrease anxiety $[2,3]$. In the electrophysiological experiment, EE could induce facilitation of long-term potentiation (LTP) in hippocampal CA1 [4]. Moreover, enriched environment can cause morphological and structural changes in the nervous system, including the enhancement of the pericaryon volume and the reduction of spontaneous apoptosis of nerve cells [5]. A number studies show that EE promotes plastic modifications of neural network including dendritic growth and branching, the formation of dendritic spines and the formation of new synaptic connections [6-8]. On the other hand, a few decades ago, it is well known that long-term social isolation (SI) would be detrimental to human health, such as increasing the risk of vascular and nervous system diseases [9]. Several neurological diseases were given special emphasis in the context of SI, such as atherosclerosis, myocardial infarction, ischemic stroke and Alzheimer's disease. SI increases the risk of future cognitive impairment and enhances the rate of memory decline in old age [10, 11]. Previous studies showed that that SI decreased spatial cognitive ability and hippocampal LTP [12, 13].

It is well known that synaptic plasticity is the cellular basis of learning and memory [14]. Learning and memory do not depend on the generation of new neurons rather than on the generation of new junctions between neurons. Mechanisms of synaptic plasticity were related to changes in presynaptic vesicle release and the number, distribution, and sensitivity of postsynaptic receptors. LTP is a continuous increase in synaptic strength through repetitive electrical stimulation, which is believed to be important for mammalian hippocampus functions in the acquisition and consolidation of memories [15]. Depotentiation (DEP) is the reversal of LTP, which is induced immediately by Low-frequency afferent stimulation (LFS) after LTP 
induction in the hippocampus. It is thought to correlate with several important physiological functions, such as prevention or elimination of memory storage [16].

Along with the continuous advancement of the electrophysiological studies of brain network, the synchronization of neural oscillations is associated with the functional changes of the neural network and related to cognitive processes [17]. Traditionally, neuronal oscillations are identified with different frequencies, delta 1-3 $\mathrm{Hz}$, theta $3-8 \mathrm{~Hz}$, alpha $8-13 \mathrm{~Hz}$, beta $13-30 \mathrm{~Hz}$ and gamma $30-100 \mathrm{~Hz}$ [18]. Each oscillation has its particular physiological function. Recently, many studies showed that the coupling between different frequencies represented a specific physiological process, such as learning and memory, emotion and social behavior [19-21]. Compared with the coupling within an identical frequency, cross-frequency coupling directly reflects the process of neural network transmission [19]. Phase-amplitude coupling (PAC) and Phase-phase coupling (PPC) are two types of cross-frequency coupling where the phase of low-frequency activity modulates the amplitude or phase of high-frequency activity $[22,23]$.

The current study was designed to determine how housing environment affected the cognitive ability of mice and explore the underlying mechanism. Morris water maze (MWM) and novel object recognition were performed to evaluate the degree of cognitive ability in mice. The signals of Local field potentials (LFPs) were recorded in the hippocampal DG regions, while modulation index (MI) was applied to measure the phase-amplitude coupling (PAC) and n:m phase locking value (n:m PLV) was used to measure the phase-phase coupling (PPC). Following the recording of LFPs, both LTP and DEP were induced by either theta burst stimulation (TBS) or low frequency stimulation (LFS), respectively. HE staining was used to detect morphology and cell density of hippocampus DG region. The density of PSD-95 in hippocampus DG and CA3 region were determined by immunofluorescence assay. Finally, Western blot was applied to investigate the level of synapse related proteins (SYP and PSD-95) and excitatory and inhibitory receptors (NR2A, NR2B and $\left.\mathrm{GABA}_{\mathrm{A}} \mathrm{R}\right)$. 


\section{Methods and materials}

\subsection{Reagents}

Anti-Synaptophysin antibody, anti-PSD-95 antibody, anti-NR2B antibody, anti-NR2A antibody, anti-GABAAR antibody, Anti-Beclin-1 antibody was bought from Cell Signaling Technology (MA, USA). Anti- $\beta$-actin antibody was purchased from Santa Cruz Biotechnology, Inc. CA (California, USA). The Alexa 488-conjugated goat anti-rabbit IgG was bought from Invitrogen (San Diego, USA). The chemiluminescent HRP substrate was purchased from Millipore Corporation (MA, USA).

\subsection{Animals and treatment}

Specific pathogen free male C57BL/6J mice, four-week-old, purchased from Laboratory Animal Center, Academy of Military Medical Science of People's Liberation Army, and reared in the animal house of Medical School, Nankai University. All experiments were carried out according to the protocol approved by the Committee for Animal Care at Nankai University and in accordance with the practices outlined in the NIH Guide for the Care and Use of Laboratory Animals.

Animals were randomly divided into three groups, which were control (CON) group $(n=6)$; enriched environment (EE) group $(n=6)$ and social isolation (SI) group $(\mathrm{n}=6)$. Mice in the EE group were raised in large $(60 \times 40 \times 35 \mathrm{~cm})$ and multilayer space and various toys such as houses, running wheels, hammocks, scales, small bells, ladders and tunnels. Objects were changed twice a week. Animals in the CON group were housed in standard cages $(36 \times 18 \times 14 \mathrm{~cm})$ with 6 mice/cage without objects. Mice in the SI group were raised in standard cages with one mouse/cage without objects. All animals were housed in different cage until 3 months of age.

\subsection{Morris water maze test}

After 3 months of treatment, mice in each group were trained and tested with the Morris water maze (MWM) (RB-100A type, Beijing, China) to examine their spatial learning and memory ability $(n=6)$. The test was performed in a circular plastic tank of $1.5 \mathrm{~m}$ diameter filled with water kept at $25^{\circ} \mathrm{C}$. A platform $(10 \mathrm{~cm}$ diameter $)$ was kept $1.5 \mathrm{~cm}$ under the surface of the water. The maze was divided into four equal 
quadrants (I-IV) with two imaginary perpendicular lines crossing in the center of tank.

The MWM test includes four consecutive stages: initial training (IT), space exploring test (SET), reversal training (RT) and reversal exploring test (RET). During the IT (1-5 d) stage, trained to find the hidden platform for 5 consecutive days, four training trials per day. In each trial, every animal was placed into the pool and permitted to search for the submerged platform for $60 \mathrm{~s}$. If a mouse failed to find the platform in $60 \mathrm{~s}$, it was gently guided to the platform location and allowed to stay on it for $10 \mathrm{~s}$, and the escape latency was recorded as $60 \mathrm{~s}$. On the 6th day of the test, the SET stage was carried out by using one trial without the platform after the last session of the IT stage at least $24 \mathrm{~h}$ later. After the platform was removed, the mice were released individually into the pool from one of the starting points and allowed to explore the pool for $60 \mathrm{~s}$. The frequency with which each mouse passed the hidden platform and the resident time that each mouse spent in the target quadrant were noted as the result of the spatial memory function, namely platform crossings and time spent in target quadrant. In addition, the other two parameters of swimming speed and distance were also recorded. Finally, the RT stage was conducted for 2 days (7-8 d) in the same way and with the same parameters as that in the IT stage. The difference was that the platform was moved into the opposite quadrant. For the RET stage, the approach and the parameters were similar to those in the SET stage. The mouse's movement was monitored by a CCD camera connected to a personal computer, through which data were collected and analyzed (Ethovision 2.0, Noldus, Wagenigen, Netherlands).

\subsection{The novel object recognition test}

The test apparatus was a white plastic box $(40 \times 40 \times 35 \mathrm{~cm})$. The objects used in this study were two cuboids $(6 \times 6 \times 4 \mathrm{~cm})$ and a cone $(6 \times 4 \mathrm{~cm})$, which were different in shape and color but similar in size $(n=6)$. Objects were placed in two opposite corners in the box. The mice were acclimated to the apparatus for $10 \mathrm{~min}$ one day before training and testing. For the training session, two cuboids were placed in the box and the exploring activity of the mouse was monitored for 10 min by using video camera. 
The retention session was carried out $2 \mathrm{~h}$ after the training session. For the training session, two objects were located in the open box, but a cone replaced one of the cuboid during training. The exploring activity was monitored for 5 min. The objects were cleaned with $10 \%$ ethanol between each mouse and session.

\subsection{In vivo electrophysiological test}

After 3 months of treatment, in vivo electrophysiological experiments were performed $(n=6)$. Both long-term potentiation (LTP) and depotentiation (DEP) between the hippocampal perforant pathway (PP) and dentate gyrus (DG) region were recorded, and signals of local field potential (LFPs) were collected as well. The mice were anesthetized with $30 \%$ urethane with a dosage of $4 \mathrm{ml} / \mathrm{kg}$ and positioned on a stereotaxic frame (SR-6 N; Narishige, Japan) for surgery. A proper incision was cut in the scalp and a hole was drilled in the skull for both the recording and stimulating electrodes. According to the mouse brain atlas [24], A concentric bipolar stimulating electrode was carefully inserted into the PP region $(3.8 \mathrm{~mm}$ posterior to the bregma, $3.0 \mathrm{~mm}$ lateral to midline, $1.5 \mathrm{~mm}$ ventral below the dura) and another monopolar extracellular stainless steel recording electrode was inserted into DG region $(2.0 \mathrm{~mm}$ anterior to the bregma, $1.4 \mathrm{~mm}$ lateral to midline, $1.5 \mathrm{~mm}$ ventral below the dura), respectively. Test stimuli were delivered to the PP every $30 \mathrm{~s}$ at an intensity that evoked a response of $70 \%$ of its maximum (range $0.3-0.5 \mathrm{~mA}$, stimulus pulse with $0.2 \mathrm{~ms}$, at $0.03 \mathrm{~Hz}$ ). After about 10 mins, LFPs in DG was recorded by Chart 5.3 software at a sampling rate of $1000 \mathrm{~Hz}$ for $10 \mathrm{~min}$. Subsequently, sampling was made under low-frequency stimulations $(0.2 \mathrm{~ms}$ at $0.05 \mathrm{~Hz})$ for $20 \mathrm{~min}$ as the baseline. After that, theta burst stimulation (TBS, 30 trains of 12 pulses at $200 \mathrm{~Hz}$ ) was delivered to induce LTP. Following TBS stimulation, the amplitude of excitatory post-synaptic potentials (fEPSPs) was recorded every $60 \mathrm{~s}$ for $1 \mathrm{~h}$. After LTP recording, low-frequency stimulation (LFS) (900 pulses of $1 \mathrm{~Hz}$ for 15 minutes) was delivered to induce DEP. Then, fEPSPs was resumed every $60 \mathrm{~s}$ for $60 \mathrm{~min}$. All initial measurements were executed in a Clampfit 10.0 (Molecular Devices, Sunnyvale, CA).

\subsection{Power spectrum density (PSD) analysis}

In this study, Multi-taper Spectral Estimations was used to measure the power in 
the hippocampal PP and DG regions $(\mathrm{n}=6)$. This method applies Slepian sequences which are orthogonal tapers to estimate the power spectrum of a signal. Given a time sequence $X_{t}, t=1,2, \cdots, N$, the multi-taper spectral estimation is:

$$
\hat{S}^{M T}(f)=\frac{1}{K} \sum_{k=1}^{K}\left|\frac{1}{N} \sum_{t=1}^{N} \exp (2 \pi i f t) u_{t}^{k} X_{t}\right|^{2}=\frac{1}{K} \sum_{k=1}^{K}\left|\tilde{X}_{k}(f)\right|^{2}
$$

$\mathrm{K}$ is the number of the Slepian sequences. $u_{n}^{k}, n=1,2, \ldots, N$ is the kth Slepian sequence and $\tilde{X}_{k}(f)$ is the tapered Fourier transform of $X_{k}$.

A window length of 20,000 (20 s) with $50 \%$ overlap was used to estimate the power spectrum.

\subsection{Phase-phase coupling (PPC)}

Phase locking value (PLV) is an important index of phase synchronization, which is widely used to measure the degree of phase variance between two signals $[25,26]$. In this study, we used a window length of 20000 (20s) with $50 \%$ overlap to calculated PLV between PP and DG $(n=6)$.

Firstly, eegfilt.m from EEGLAB toolbox was applied to decompose the original PP and DG LFPs into theta frequency bands (3-8 Hz), alpha frequency bands (8-13 $\mathrm{Hz})$, LG frequency bands $(30-50 \mathrm{~Hz})$ and $\mathrm{HG}$ frequency bands $(50-80 \mathrm{~Hz})$ [27]. The bandwidth is $1 \mathrm{~Hz}$. The step is $1 \mathrm{~Hz}$. Then, the instantaneous phases of the filtered LFPs in the above frequency bands were attracted by Hilbert transform and were signed as $\phi_{P P}(f, t)$ and $\phi_{D G}(f, t)$. The frequency-dependent PLV was defined as:

$$
P L V(f)=\left|\frac{1}{N} \sum_{j=1}^{N} \exp \left(\mathrm{i}\left[\phi_{P P}(f, j \Delta t)-\phi_{D G}(f, j \Delta t)\right]\right)\right|
$$

$\mathrm{N}$ was the length of the LFP signal and $1 / \Delta t$ was the sampling frequency.

Furthermore, we applied this method to measure the phase-phase coupling between PP alpha rhythm $(8-13 \mathrm{~Hz})$ and DG LG $(30-50 \mathrm{~Hz})$ or HG $(50-80 \mathrm{~Hz})$ rhythms. The LFPs in PP area were filtered into alpha rhythm. The LFPs in DG area were filtered into LG and HG rhythms, respectively. Then, the instantaneous phases $\phi(t), t=1,2, \cdots, N$ of the filtered LFPs in the above frequency bands were obtained 
by Hilbert transform. $N$ was the length of the signal. Then the radial distance (r) value was defined as:

$$
r_{n: m}=\left|\frac{1}{N} \sum_{j=1}^{N} \exp \left(\mathrm{i}\left[\mathrm{m}^{*} \phi_{\text {alpha }}(\mathrm{j})-\mathrm{n}^{*} \phi_{\text {gamma }}(\mathrm{j})\right]\right)\right|
$$

In this study, we calculated the distribution of $r_{n: m}$ for different rations $(1: 1,1: 2, \ldots, 1: 20)$. A larger value of radial distance $(r)$ indicated a more unimodal distribution of $\phi_{n: m}(t)=m * \phi_{\text {alpha }}(t)-n * \phi_{\text {gamma }}(t)$, and suggested a stronger phase coupling. Rayleigh test was used for the uniformity test [28, 29].

\subsection{Phase amplitude coupling (PAC)}

Modulation index (MI) was used to measure the phase-amplitude coupling (PAC) between PP low frequency rhythm and DG high frequency rhythm $(n=6)$. The method produced a complex signal $Z_{f p h, f a m}(t)=\mathrm{A}_{f a m}(t) * \exp \left(i * \phi_{f p h}(t)\right)$. In this study, $\phi_{f p h}(\mathrm{t})$ represented the instantaneous phase of the low frequency rhythm and $A_{\text {fam }}(\mathrm{t})$ represented the instantaneous amplitude of the high frequency rhythm. The MI value is:

$$
M I_{\text {raw }}=\operatorname{abs}\left(\operatorname{mean}\left(Z_{f p h, f a m}(t)\right)\right)
$$

Surrogate data are produced by shuffling the amplitude time series with a time lag $\tau$ between $\phi_{f p h}(\mathrm{t})$ and $A_{f a m}(\mathrm{t})$.

$$
Z_{\text {surr }}(t, \tau)=A_{\text {fam }}(t+\tau) \exp \left(i * \phi_{f p h}(t)\right)
$$

The normalized MI was defined as:

$$
M I_{\text {Norm }}=\left(\mathrm{MI}_{\text {raw }}-\mu\right) / \sigma
$$

$\mu$ was the mean value and $\sigma$ was the standard deviation of the surrogate data, respectively.

In the study, we used the convolution with complex Morlet wavelets of the depth 7 to generate the phase of PP low frequency bands $(\phi(t), 1-15 \mathrm{~Hz}$, band $=1 \mathrm{~Hz}$, 
step $=1 \mathrm{~Hz}$ ) and DG gamma frequency bands $\left(A_{\text {gamma }}(\mathrm{t}), 30-80 \mathrm{~Hz}\right.$, band $=1 \mathrm{~Hz}$, step $=1 \mathrm{~Hz}$ ). A window length of 40s (40000) with $50 \%$ overlap was adopted.

\subsection{Hematoxylin/eosin staining}

After 3 months of treatment, their brains were immediately washed with $0.1 \mathrm{M}$ phosphate buffer $(\mathrm{pH}=7.4)$. Subsequently, the brains were embedded in OCT compound (Tissue-Tek, Miles) at $-20{ }^{\circ} \mathrm{C}$ for tissue sectioning. The coronary sliced in $20 \mu \mathrm{m}$ thick coronary slices for hematoxylin and eosin (HE) staining. Finally, the sections were photographed on a Leica microscope (Wetzlar, Germany). The density of DG cells was presented by the number of cells per $\mathrm{mm}^{2}$ area. The results were counted in 3 randomly chosen fields from one slide, with 5 slides of one mouse, and there were 5 mice for each group.

\subsection{Immunofluorescence}

The brains were embedded in OCT compound (Tissue-Tek, Miles) at $-20{ }^{\circ} \mathrm{C}$ for tissue sectioning $(n=3)$. The coronary sliced in $20 \mu \mathrm{m}$ thick coronary slices for Immunofluorescence staining. And then they were washed with PBS, and then permeabilized with $0.5 \%$ Triton X-100 and blocked with $10 \%$ NGS for $2 \mathrm{~h}$ at room temperature. Subsequently, the cells were incubated with primary antibody (1:500). After washing with PBS, they were incubated with the Alexa 488 conjugated goat anti-mouse IgG secondary antibody (1:1000). Thereafter, the cell nuclei were stained by DAPI. Samples were examined under a fluorescence microscope (Olympus FV1000, Japan).

\subsection{Western blot assay}

After 3 months of treatment, the hippocampus of mouse was separated and stored at $-80^{\circ} \mathrm{C}$ for the preparation of tissue lysates $(n=3)$. The method of protein extraction was described in our previous studies [30, 31]. Each hippocampus was mashed with a grinder and $200 \mu \mathrm{l}$ lysis buffer (Beyotime Biotechnology, Haimen, China) containing 1\% Phenyl methane sulfonyl fluoride (PMSF). The Lysates were centrifuged at 12000 $\mathrm{r} / \mathrm{min}$ for $20 \mathrm{~min}$ at $4^{\circ} \mathrm{C}$. And then the protein concentration was determined using the BCA Protein Assay Kits (Beyotime Biotechnology, Haimen, China). Finally, the 
supernatant was mixed with loading buffer (ratio is $4: 1$ ) and boiled at $100{ }^{\circ} \mathrm{C}$ for 10 $\min$.

The method of western blotting was modified on the basis of previous studies [32]. Total proteins were subjected to electrophoresis in 10\%-13\% SDS-PAGE gel, after which they were transferred to a poly vinylidene fluoride (PVDF) membrane. Membranes were then incubated in a 5\% milk solution in TBST (Tris-buffered saline with $0.05 \%$ Tween 20$)$ at $25^{\circ} \mathrm{C}$, washed and incubated in primary antibody $(1: 1000)$ overnight at $4{ }^{\circ} \mathrm{C}$. After washing four times with TBST and once with TBS for $10 \mathrm{~min}$ each time, the membranes were incubated with horseradish peroxidase (HRP)-conjugated secondary antibodies $(1: 2000)$ for $40 \mathrm{~min}$ at $25^{\circ} \mathrm{C}$. After washing four times with TBST and once with TBS for 10 min each time, protein band intensities were detected with HRP substrate (Millipore, USA) by using Tanon 5500 chemiluminescent imaging system (Tanon Science \& Technology, China). Finally, the quantitation analysis was performed by Photoshop CS6 and compared to the loading control proteins $\beta$-actin.

\subsection{Data and Statistical Analysis}

All data were presented as mean \pm SEM. Two-way repeated measures ANOVA was used to analyze the results of Morris water maze test and novel object recognition test. All the LFP results, such as PLV, MI and n: m PLV were analyzed by Student's t-test. The statistical differences of the Western blot results, such as PSD-95, SYP, NR 2A, NR 2B, GABAAR were detected by one way ANOVA and post-hoc comparison was done by LSD test. All the analyses were performed using SPSS 17.0 software. Significant differences were taken when $\mathrm{P}<0.05$. 


\section{Results}

\subsection{Performance of EE and SI Mice in MWM Experiment}

To evaluate the impact of enriched environment and social isolation on hippocampal-depend learning and memory ability, the Morris water maze task was performed.

During the IT stages, two-way mixed ANOVA showed significant effect of housing environment $[\mathrm{F}(2,15)=74.032, \mathrm{P}<0.001]$ and day $[\mathrm{F}(4,12)=43.081, \mathrm{P}<$ 0.001], but no significant interaction effect among housing environment $\times$ day [F (8, $26)=0.686, \mathrm{P}>0.05]$. In the IT stage, animals received 5 days consecutive training to learn the location of a hidden platform. As shown in Fig.1a, there were lower latencies at day $2-5(\mathrm{p}<0.05)$ in the EE group and higher latencies at day $4-5(\mathrm{p}<0.05)$ in the SI group compared to that in the CON group. During the RT stages, two-way mixed ANOVA showed significant effect of housing environment $[\mathrm{F}(2,15)=13.866, \mathrm{P}<$ $0.001]$ and day $[\mathrm{F}(1,15)=20.112, \mathrm{P}<0.001]$, but no significant interaction effect among housing environment $\times$ day $[\mathrm{F}(8,26)=0.212, \mathrm{P}>0.05]$.In the RT stage, there was lower latency at day $2(\mathrm{p}<0.05)$ in the EE group and higher latency at day 2 (p < 0.05) in the SI group compared to that in the CON group. In addition, there were no significant difference of the average swim speed among these three groups for both days (Fig. 1b, p > 0.05). In the SET and RET stages (Fig. 1c-f), EE mice preformed higher quadrant occupancy and plant form crossing ( $\mathrm{p}<0.05)$, but SI mice preformed lower quadrant occupancy and plant form crossing $(\mathrm{p}<0.01)$.

\subsection{Performance of EE and SI Mice in the novel object recognition test}

To examine the effect of enriched environment and social isolation on object recognition memory, a novel object recognition test was carried out. In both rodents' and primates' brains, recognition memory is strongly related to hippocampal functional integrity[33]. In the retention session, the time for mice to explore new objects was T1, and the time to explore old objects was T2. The level of recognition index (RI) calculated through the formula: $\mathrm{RI}=\mathrm{T} 2 /(\mathrm{T} 1+\mathrm{T} 2) \times 100 \%$ [34]. It was found that there was higher recognition index in the EE group $(\mathrm{p}<0.01)$ and lower recognition index $(\mathrm{p}<0.01)$ in the SI group compared to that in the CON (Fig. 1g). 
Moreover, the visit times and latency to novel object are higher in the EE group and lower in the SI group than that in the CON group (Fig. 1h and 1i). In addition, the walking speed is no significantly different in three groups (Fig. 2j).

\subsection{Measurement of LTP and DEP in the PP-DG pathway}

As shown in Fig. 3a, during $20 \mathrm{~min}$ of low-frequency test stimulations, the fEPSPs baseline before TBS was quite stable. After TBS stimulation, the fEPSPs slopes were obviously increased in the following 1 hour in each group. Meanwhile, the fEPSPs slopes were visibly decreased in the following 1 hour in each group after LFS stimulation. Both LTP and DEP at the last $10 \mathrm{~min}$ of fEPSPs slopes were measured. It can be seen that there is higher LTP (Fig. 3b, p < 0.01) and lower DEP in the EE group (Fig. 3c, p < 0.05) compared to that in the CON group. However, SI mice exhibited lower LTP (Fig. 3b, p < 0.01) and higher DEP (Fig. 3c, p < 0.01) compared with normal animals.

\subsection{Power spectrum of LFP}

With the purpose of investigating the power distribution at different frequency bands in either PP or DG areas, PSD analysis was used. As shown in Fig. S1, it was found that there were observable stripes in mice, suggesting that there were relatively stable neural activities in these three developmental stages.

\subsection{Effect of EE and SI on phase synchronization between PP and DG}

Synchronous oscillations in physiological rhythms play crucial roles in neural communication between different regions. Consequently, the phase synchronization between PP and DG regions in theta, alpha, LG and HG frequency bands were measured by PLV method. As shown in Fig.4a, the value of PLV at alpha frequency band was bigger in the EE group $(\mathrm{p}<0.05)$ and smaller in the SI group $(\mathrm{p}<0.05)$ than that in the CON group. There was no significant difference of phase locking values at theta, LG and HG frequency bands in the three groups ( $\mathrm{p}>0.05)$.

\subsection{Effect of EE and SI on cross frequency phase synchronization between}

\section{PP and DG region}

To detect the cross frequency alpha-gamma phase coupling quantitatively, the radial distance values ( $r$ ) of the circular distribution was measured from the phase 
differences between $m *$ alpha frequency bands in the PP region and $n * L G$ and $n * H G$ frequency bands in the DG region phases for 20 ratios. As shown in Fig. S2a, there was a distinct peak at $n: m=4: 1$ ratio, suggesting that there were 4 DG low gamma circles in one PP alpha ring in these three groups. As shown in Fig. 4b, post hoc LSD test showed that at 4:1 ratio, n: m PLV strength significantly increased in EE mice compared with that in $\mathrm{CON}$ mice $(\mathrm{p}<0.05)$. At $3: 1$ and $4: 1$ ratios, SI mice significantly decreased n: m PLV strength both compared with CON and EE mice (p $<0.05)$. At 5:1 ratios, SI mice significantly increased n: m PLV strength both compared with CON and EE mice $(\mathrm{p}<0.01)$. As shown in Fig. 4c, EE mice significantly increased the total n: m PLV strength both compared with CON and SI mice $(\mathrm{p}<0.05)$. Moreover, SI mice decreased the total $\mathrm{n}$ : m PLV strength compared with CON mice, although the changes did not reach significance (Fig. 4c, p=0.09).As shown in Fig. S2b there were a distinct peak at $n: m=7: 1$ and 8:1 ratios between alpha in PP region and HG in DG region in three groups. As shown in Fig. 4d, post hoc LSD test showed that at 8:1and 9:1 ratios EE mice significantly increased n: m PLV strength both compared with CON and SI mice $(\mathrm{p}<0.05)$. At 7:1 ratios, SI mice significantly decreased n: m PLV strength both compared with CON and EE mice (p $<0.05)$. As shown in Fig. 4e, EE mice significantly increased the total n: m PLV strength both compared with CON and SI mice ( $\mathrm{p}<0.001)$. Moreover, SI mice decreased the total n: m PLV strength compared with CON mice, although the changes did not reach significance (Fig. 4e, p =0.07).

\subsection{Effect of EE and SI on cross frequency phase-amplitude coupling}

\section{between PP and DG region}

In order to measure the cross frequency phase-amplitude coupling between low frequency bands $(1-20 \mathrm{~Hz})$ in the PP and gamma frequency bands $(30-100 \mathrm{~Hz})$ in the DG, MI algorithm was employed. Representative examples of MI results in the three groups were shown in Fig.4f. Moreover, it was found that the strength of alpha-gamma PAC was much stronger in the EE mice $(\mathrm{p}<0.05)$ and visibly weaker in the SI group ( $\mathrm{p}<0.05)$ compared to that in the CON group (Fig.4g).

\subsection{Effect of EE and SI on neuronal density of DG region}


HE staining was used to detect the cell density of neurons in DG region. As showed in Fig. 5a\& Fig. 5b, the density of DG cells has no significantly change in the mice reared in different housing environment.

\subsection{Effect of EE and SI on the level of SYP and PSD-95}

In order to detect the underlying molecular mechanism of the effect of EE and SI on synaptic plasticity in C57 mice, we measured the levels of synaptophysin (SYP) and postsynaptic density protein 95 (PSD-95), which were two commonly used presynaptic and postsynaptic markers, respectively. It can be seen that the level of PSD-95 is higher in the EE group and lower in the SI group than that in the CON group (Fig. 5e, p < 0.01). Meanwhile, there were no significant differences of SYP level between the three groups (Fig. 5d).

Further, immunofluorescence staining was used to detect the PSD-95 density in DG and CA3 region of hippocampus. As showed in Fig. 5f, green fluorescence represents PSD-95, blue fluorescence represents the nucleus. It is easy to see the green fluorescence is higher in the EE group and lower in the SI group than that in the CON group in both DG and CA3 region.

\subsection{Effect of EE and SI on the Level of NR 2A, NR2B and GABA $A_{A} R$}

To examine the effects of EE and SI on level of postsynaptic excitatory and inhibitory receptors, two excitatory receptors NR2A and NR2B and an inhibitory receptor GABAAR were distinguished (Fig. 6a). As shown in Fig. 6b, NR2B level was significantly higher in the EE group compared to that in the CON group ( $<<0.05)$. There was no significant difference of NR2A between the EE group and the CON group (Fig. 6c, p=0.072). In addition, the level of both NR2A (p<0.05) and NR2B (p $<0.01$ ) was much lower in the SI group than that in the EE group (Fig. 6b \& 6c). As shown in Fig. 6d, GABAAR levels were significantly higher in the SI group compared to that in the CON group ( $\mathrm{p}<0.05$ ), but there was no significant difference of the $\mathrm{GABA}_{\mathrm{A}} \mathrm{R}$ level between the EE group and the CON group. The above data suggested that enriched environment mainly impacted excitatory synaptic density and social isolation mainly affected inhibitory synaptic density. 


\section{Discussion}

In this study, we performed a wide-ranging analysis of the potential mechanism about the effects of housing environment on cognitive ability. It showed that EE improved learning and memory and SI reduced them, while EE significantly enhanced synaptic plasticity. Moreover, EE considerably increased both phase-synchronization and cross-frequency coupling but SI effectively decreased them. In addition, Western data showed that EE increased the level of postsynaptic excitatory receptors, and SI increased the level of postsynaptic inhibitory receptors. It suggests that housing environment performs a significant intervention on the cognitive functions through changing the balance of excitatory and inhibitory synaptic density.

\section{The effect of synaptic plasticity and neural oscillations on cognition ability}

A large number of previous studies showed that housing environment could affect the cognitive ability and synaptic plasticity of experimental animals[4, 35, 36]. The data, obtained from the present study, are in accord with the above results. Moreover, our results further exhibited that housing environment impacted the cognitive flexibility. In the RT stage of MWM, the platform was artificially moved into the contralateral quadrant, the animals in the SI group stubbornly search the platform in the original location, but EE mice were able to change the strategy to search the moved platform. Furthermore, housing environment was not only involved in previously acquired behavior strategies but also related to establishing new strategies. LTP and depotentiation are thought to regulate learning and memory, and other types of experience-dependent plasticity in the mammalian brain [37-39]. There is a strong correlative evidence that LTP is the key to the formation and storage of memory, and LTD or depotentiation (LTP reversal) is the mechanism for removing unwanted or pathological memories [40-42]. In the present study, either EE or SI significantly modified both LTP and depotentiation of mice. The results suggested that the regulation of LTP and depotentiation by housing environment was the fundamental mechanism of the change of cognitive ability and cognitive flexibility in behavioral experiments.

It is well known that distributed neuronal is coordinated by neural oscillations, 
which underlies cognitive processing $[18,43]$. Previous studies have mostly focused on the coupling between alpha and gamma rhythms on neural communication and synaptic plasticity [44]. However, in the present study, we found that the coupling of the alpha-gamma rhythms was more pronounced in the mice reared in different environments. Alpha rhythm plays an important role in inhibiting task-irrelevant brain regions $[45,46]$. Moreover, alpha rhythms are directly or indirectly associated with the process of working memory, conscious somatosensory perception, visuospatial attention and creative idea generation [47-50]. In perceptual learning, 64\% of the observed variability in the learning outcome can be ascribed to the activity of ongoing alpha frequency band [51]. The evidence show that alpha rhythm is possible to be a potential underlying mechanism of perceptual learning. Moreover, gamma frequency band is closely related to various cognitive processes, including consciousness, perception, attention and memory [52-54]. These cognitive processes are possibly associated with alpha-gamma cross frequency PAC [55-57]. Therefore, enhancing neural coupling between alpha and gamma rhythms plays a significant role in the learning and memory.

DG is a special region of the hippocampus where neurogenesis persists in the DG region of adult animal [58]. In this study, there was no change in the cell density of the DG region in the three groups, which suggested that housing environment did not affect the number of neuron. Accordingly, housing environment-induced the change of cognition ability may be associated with the level of synaptic related proteins. The level of SYP and PSD-95 were closely related to synaptic plasticity and learning and memory [59, 60]. Synaptophysin is an important synaptic vesicle membrane protein, and its expression is closely related to the number of presynaptic vesicles [61]. PSD-95 is a postsynaptic scaffold protein, which plays a role in the support and anchoring of postsynaptic receptors such as a-amino-3-hydroxy-5-methyl-4-isoxazole propionic acid (AMPA) and $\mathrm{N}$-methyl-D-aspartate (NMDA) receptors [62]. In the present study, it was found that both EE and SI changed the level of PSD-95, suggesting that the postsynaptic mechanism was involved in the effect of hosing environment on synaptic plasticity of 
mice.

The key role of excitatory and inhibitory synaptic density balance in synaptic plasticity

As major postsynaptic excitatory amino acid receptors in the central neuron system, NMDA receptors play vital role in learning and memory [63]. Activation of NMDA receptors can increase the concentration of postsynaptic $\mathrm{Ca}^{2+}$ and eventually induce LTP and long-term depression (LTD) [64, 65]. The level of NMDA receptors at the synapse was directly regulated by PSD-95 [66, 67]. Prior studies have suggested that the cytoplasmic tails of NMDA receptor subunits interact with a prominent PSD-95 [68]. PSD-95 enhances NMDA receptors surface expression by increasing the rate of channel insertion and decreasing the rate of channel internalization [69]. It can be seen that EE enhances the level of NMDA receptors, especially for NR 2B, which may be associated with the increase of PSD-95 density.

A considerable evidence has been provided the involvement of the $\mathrm{GABA}_{\mathrm{A}}$ receptors in cognitive processes. The enhancement of $\mathrm{GABA}_{\mathrm{A}}$ receptors significantly impaired memory ability and the reduction of GABAA receptors effectively facilitate it in mice [70]. The synaptic density in the visual cortex pyramidal GABAergic neurons of the dark reared mice was significantly enhanced [71]. In addition, the activation of GABAergic neurons caused depression symptoms in mice, while the inhibition of GABAergic neurons in depression model mice significantly improved depression symptoms [72]. In addition, knocking out the $\alpha 4$ subunit of the GABAA receptors could improve the decline in synaptic plasticity and spatial cognitive ability in adolescence [73]. In the study, the increase of GABAA receptors level may be a possible mechanism of synaptic plasticity and learning and memory impairment in SI mice.

Excitatory and inhibitory synapses have a large difference in distribution and structure. Glutamatergic synapses are mainly found in the dendritic spines [74], while GABAergic synapses mainly distributed in the dendritic skeleton, the cell body and the neurite [75]. Excitatory synapses contain a postsynaptic density (PSD) region; whereas inhibitory synapses do not have this characteristic [76]. The information 
transfer in the brain depends on the balance between excitatory and inhibitory functions of the neuronal network [77]. The excitatory and inhibitory balance is essential for brain function and may be of particular importance to cognition ability. At the level of a single neuron, the balance is involved in the ratio of excitatory and inhibitory synaptic density. The activity of glutamatergic synapses can make the cell polarization and increase the probability of action potential evoked; and the GABAergic synapses are just the opposite [78]. Moreover, GABAergic neurons is involved in the generation of gamma oscillations [79]. The interaction between glutamatergic and GABAergic neurons has great relevance for oscillation coupling in low-frequency and high-frequency [80]. Thus, in this study, the balance of excitatory and inhibitory synaptic density is directly related to synaptic plasticity and neural phase-coupling in the housing environment.

However, recent papers showing that neuromodulation systems such as that operated by adenosine A2AR can format memory and plasticity in the absence of any alterations of synapse morphology or of glutamatergic mediators [81-83]. Therefore, further study is to explore whether there are other mechanisms involved in the change of animal behavior caused by housing environment.

\section{Conclusion}

In summary, the present study was to investigate the effects of housing environment on cognitive ability and synaptic plasticity in C57 mice, and to explore its potential molecular mechanism. The data suggested that the cognitive ability, synaptic plasticity and the pattern of neural activities were significantly impacted by housing environment through changing the balance of excitatory and inhibitory synaptic density. The results will help to explore the formation mechanism and a safe and effective treatment in certain nerve injuries and neurodegenerative diseases. 


\section{Declarations}

\section{Ethics approval and consent to participate}

All procedures were carried out according to the NIH Guide for the Care and Use of Laboratory Animals and approved by the Ethical Commission at Nankai University (20160004).

\section{Consent for publication}

Not applicable.

\section{Availability of data and materials}

The datasets used and/or analyzed during the current study are available from the corresponding author on reasonable request.

\section{Competing interests}

We confirm that there are no known conflicts of interest associated with this publication and there has been no significant financial support for this work that could have influenced its outcome.

\section{Funding}

This work was supported by grants from the National Natural Science Foundation of China (31171053, 31900733), 111 Project (B08011) and China Postdoctoral Science Foundation (2019M651012).

\section{Authors' contributions}

Hui Wang, Xiaxia Xu and Tao Zhang conceived and designed the experiment; Hui Wang, Xiaxia Xu and Jing Gao performed the experiments and analyzed the data; and Hui Wang and Tao Zhang wrote the manuscript. All authors read and approved the final manuscript.

\section{Acknowledgements}


566

Not applicable

567 


\section{references}

1. Leggio MG, Mandolesi L, Federico F, Spirito F, Ricci B, Gelfo F, Petrosini L: Environmental enrichment promotes improved spatial abilities and enhanced dendritic growth in the rat. Behav Brain Res 2005, 163:78-90.

2. Lee EH, Hsu WL, Ma YL, Lee PJ, Chao CC: Enrichment enhances the expression of sgk, a glucocorticoid-induced gene, and facilitates spatial learning through glutamate AMPA receptor mediation. Eur J Neurosci 2003, 18:2842-2852.

3. Bennett JC, McRae PA, Levy LJ, Frick KM: Long-term continuous, but not daily, environmental enrichment reduces spatial memory decline in aged male mice. Neurobiol Learn Mem 2006, 85:139-152.

4. Malik R, Chattarji S: Enhanced intrinsic excitability and EPSP-spike coupling accompany enriched environment-induced facilitation of LTP in hippocampal CA1 pyramidal neurons. $J$ Neurophysiol 2012, 107:1366-1378.

5. Li HY, Dokas LA, Godfrey DA, Rubin AM: Remodeling of synaptic connections in the deafferented vestibular nuclear complex. Journal of Vestibular Research-Equilibrium \& Orientation 2002, 12:167-183.

6. West RW, Greenough WT: Effect of environmental complexity on cortical synapses of rats: preliminary results. Behav Biol 1972, 7:279-284.

7. Greenough WT, Volkmar FR: Pattern of dendritic branching in occipital cortex of rats reared in complex environments. Exp Neurol 1973, 40:491-504.

8. Singh P, Heera PK, Kaur G: Expression of neuronal plasticity markers in hypoglycemia induced brain injury. Mol Cell Biochem 2003, 247:69-74.

9. Friedler B, Crapser J, McCullough L: One is the deadliest number: the detrimental effects of social isolation on cerebrovascular diseases and cognition. Acta Neuropathol 2015, 129:493-509.

10. Bassuk SS, Glass TA, Berkman LF: Social disengagement and incident cognitive decline in community-dwelling elderly persons. Ann Intern Med 1999, 131:165-+.

11. Ertel KA, Glymour MM, Berkman LF: Effects of social integration on preserving memory function in a nationally representative US elderly population. Am J Public Health 2008, 98:1215-1220.

12. Kamal A, Ramakers GM, Altinbilek B, Kas MJ: Social isolation stress reduces hippocampal long-term potentiation: effect of animal strain and involvement of glucocorticoid receptors. Neuroscience 2014, 256:262-270.

13. Quan MN, Tian YT, Xu KH, Zhang T, Yang Z: Post weaning social isolation influences spatial cognition, prefrontal cortical synaptic plasticity and hippocampal potassium ion channels in Wistar rats. Neuroscience 2010, 169:214-222.

14. Eichenbaum H: Learning from LTP: a comment on recent attempts to identify cellular and molecular mechanisms of memory. Learn Mem 1996, 3:61-73.

15. Kemp A, Manahan-Vaughan D: Hippocampal long-term depression: master or minion in declarative memory processes? Trends Neurosci 2007, 30:111-118.

16. Kulla A, Reymann KG, Manahan-Vaughan D: Time-dependent induction of depotentiation in the dentate gyrus of freely moving rats: involvement of group 2 metabotropic glutamate receptors. Eur J Neurosci 1999, 11:3864-3872.

17. Zhang T: Neural oscillations and information flow associated with synaptic plasticity. Sheng 
18. Buzsaki G, Draguhn A: Neuronal oscillations in cortical networks. Science 2004, 304:1926-1929.

19. Berman JI, Liu S, Bloy L, Blaskey L, Roberts TP, Edgar JC: Alpha-to-gamma phase-amplitude coupling methods and application to autism spectrum disorder. Brain Connect 2015, 5:80-90.

20. $\mathrm{Xu} \mathrm{X}, \mathrm{An} \mathrm{L}, \mathrm{Mi} \mathrm{X}$, Zhang $\mathrm{T}$ : Impairment of cognitive function and synaptic plasticity associated with alteration of information flow in theta and gamma oscillations in melamine-treated rats. PLoS One 2013, 8:e77796.

21. Shang $X, X u$ B, Li Q, Zhai B, Xu X, Zhang T: Neural oscillations as a bridge between glutamatergic system and emotional behaviors in simulated microgravity-induced mice. Behav Brain Res 2017, 317:286-291.

22. Li Q, Zheng CG, Cheng N, Wang YY, Yin T, Zhang T: Two generalized algorithms measuring phase-amplitude cross-frequency coupling in neuronal oscillations network. Cogn Neurodyn 2016, 10:235-243.

23. Zheng $\mathrm{C}$, Zhang T: Alteration of phase-phase coupling between theta and gamma rhythms in a depression-model of rats. Cogn Neurodyn 2013, 7:167-172.

24. Paxinos GF, Franklin K: The Mouse Brain In Stereotaxic Coordinates. Elsevier Academic Press; 2003.

25. Lachaux JP, Rodriguez E, Martinerie J, Varela FJ: Measuring phase synchrony in brain signals. Human Brain Mapping 1999, 8:194-208.

26. $\mathrm{Xu} X X$, Zheng CG, Zhang T: Reduction in LFP cross-frequency coupling between theta and gamma rhythms associated with impaired STP and LTP in a rat model of brain ischemia. Frontiers in Computational Neuroscience 2013, 7:1-8.

27. Delorme A, Makeig S: EEGLAB: an open source toolbox for analysis of single-trial EEG dynamics including independent component analysis. J Neurosci Methods 2004, 134:9-21.

28. Tass P, Rosenblum MG, Weule J, Kurths J, Pikovsky A, Volkmann J, Schnitzler A, Freund HJ: Detection of $\mathbf{n}: \mathbf{m}$ phase locking from noisy data: Application to magnetoencephalography. Physical Review Letters 1998, 81:3291-3294.

29. Belluscio MA, Mizuseki K, Schmidt R, Kempter R, Buzsaki G: Cross-Frequency Phase-Phase Coupling between Theta and Gamma Oscillations in the Hippocampus. Journal of Neuroscience 2012, 32:423-435.

30. Liu C, Xu X, Gao J, Zhang T, Yang Z: Hydrogen Sulfide Prevents Synaptic Plasticity from VD-Induced Damage via Akt/GSK-3beta Pathway and Notch Signaling Pathway in Rats. Mol Neurobiol 2015.

31. Fu J, Wang H, Gao J, Yu M, Wang R, Yang Z, Zhang T: Rapamycin Effectively Impedes Melamine-Induced Impairments of Cognition and Synaptic Plasticity in Wistar Rats. Mol Neurobiol 2016.

32. Wang H, Gao N, Li Z, Yang Z, Zhang T: Autophagy Alleviates Melamine-Induced Cell Death in PC12 Cells Via Decreasing ROS Level. Mol Neurobiol 2016, 53:1718-1729.

33. Squire LR, Stark CE, Clark RE: The medial temporal lobe. Annu Rev Neurosci 2004, 27:279-306.

34. Mumby DG, Glenn MJ, Nesbitt C, Kyriazis DA: Dissociation in retrograde memory for object discriminations and object recognition in rats with perirhinal cortex damage. Behav Brain 
Res 2002, 132:215-226.

35. de Jong IC, Prelle IT, van de Burgwal JA, Lambooij E, Korte SM, Blokhuis HJ, Koolhaas JM: Effects of environmental enrichment on behavioral responses to novelty, learning, and memory, and the circadian rhythm in cortisol in growing pigs. Physiol Behav 2000, 68:571-578.

36. Ibi D, Takuma K, Koike H, Mizoguchi H, Tsuritani K, Kuwahara Y, Kamei H, Nagai T, Yoneda Y, Nabeshima T, Yamada K: Social isolation rearing-induced impairment of the hippocampal neurogenesis is associated with deficits in spatial memory and emotion-related behaviors in juvenile mice. J Neurochem 2008, 105:921-932.

37. Bliss TV, Collingridge GL: A synaptic model of memory: long-term potentiation in the hippocampus. Nature 1993, 361:31-39.

38. Martin SJ, Grimwood PD, Morris RG: Synaptic plasticity and memory: an evaluation of the hypothesis. Annu Rev Neurosci 2000, 23:649-711.

39. Zhang L, Meng K, Li YH, Han TZ: NR2A-containing NMDA receptors are required for L-LTP induction and depotentiation in CA1 region of hippocampal slices. Eur J Neurosci 2009, 29:2137-2144.

40. Lynch MA: Long-term potentiation and memory. Physiol Rev 2004, 84:87-136.

41. Lin CH, Lee CC, Huang YC, Wang SJ, Gean PW: Activation of group II metabotropic glutamate receptors induces depotentiation in amygdala slices and reduces fear-potentiated startle in rats. Learn Mem 2005, 12:130-137.

42. Morato X, Goncalves FQ, Lopes JP, Jauregui O, Soler C, Fernandez-Duenas V, Cunha RA, Ciruela F: Chronic adenosine A2A receptor blockade induces locomotor sensitization and potentiates striatal LTD IN GPR37-deficient mice. J Neurochem 2019, 148:796-809.

43. Engel AK, Fries $P$, Singer W: Dynamic predictions: oscillations and synchrony in top-down processing. Nat Rev Neurosci 2001, 2:704-716.

44. Fell J, Axmacher $\mathrm{N}$ : The role of phase synchronization in memory processes. Nat Rev Neurosci 2011, 12:105-118.

45. Jokisch $D$, Jensen 0 : Modulation of gamma and alpha activity during a working memory task engaging the dorsal or ventral stream. Journal of Neuroscience 2007, 27:3244-3251.

46. Sauseng P, Klimesch W, Heise KF, Gruber WR, Holz E, Karim AA, Glennon M, Gerloff C, Birbaumer N, Hummel FC: Brain Oscillatory Substrates of Visual Short-Term Memory Capacity. Current Biology 2009, 19:1846-1852.

47. Jensen O, Gelfand J, Kounios J, Lisman JE: Oscillations in the alpha band (9-12 $\mathbf{~ H z )}$ increase with memory load during retention in a short-term memory task. Cerebral Cortex 2002, 12:877-882.

48. Palva S, Linkenkaer-Hansen K, Naatanen R, Palva JM: Early neural correlates of conscious somatosensory perception. J Neurosci 2005, 25:5248-5258.

49. Buffalo EA, Fries P, Landman R, Buschman TJ, Desimone R: Laminar differences in gamma and alpha coherence in the ventral stream. Proc Natl Acad Sci U S A 2011, 108:11262-11267.

50. Fink A, Benedek M, Grabner RH, Staudt B, Neubauer AC: Creativity meets neuroscience: experimental tasks for the neuroscientific study of creative thinking. Methods 2007, 42:68-76.

51. Freyer F, Becker R, Dinse HR, Ritter P: State-dependent perceptual learning. J Neurosci 2013, 33:2900-2907. 
52. Gruber T, Muller MM: Effects of picture repetition on induced gamma band responses, evoked potentials, and phase synchrony in the human EEG. Cognitive Brain Research 2002, 13:377-392.

53. Babiloni C, Babiloni F, Carducci F, Cincotti F, Rosciarelli F, Arendt-Nielsen L, Chen AC, Rossini PM: Human brain oscillatory activity phase-locked to painful electrical stimulations: a multi-channel EEG study. Hum Brain Mapp 2002, 15:112-123.

54. Tallon-Baudry C, Bertrand O, Peronnet F, Pernier J: Induced gamma-band activity during the delay of a visual short-term memory task in humans. J Neurosci 1998, 18:4244-4254.

55. Bahramisharif A, van Gerven MAJ, Aarnoutse EJ, Mercier MR, Schwartz TH, Foxe JJ, Ramsey NF, Jensen O: Propagating Neocortical Gamma Bursts Are Coordinated by Traveling Alpha Waves. Journal of Neuroscience 2013, 33:18849-18854.

56. Foster BL, Parvizi J: Resting oscillations and cross-frequency coupling in the human posteromedial cortex. Neuroimage 2012, 60:384-391.

57. Roux F, Wibral M, Singer W, Aru J, Uhlhaas PJ: The phase of thalamic alpha activity modulates cortical gamma-band activity: evidence from resting-state MEG recordings. J Neurosci 2013, 33:17827-17835.

58. Cameron HA, Gould E: Adult neurogenesis is regulated by adrenal steroids in the dentate gyrus. Neuroscience 1994, 61:203-209.

59. Schmitt U, Tanimoto N, Seeliger M, Schaeffel F, Leube RE: Detection of behavioral alterations and learning deficits in mice lacking synaptophysin. Neuroscience 2009, 162:234-243.

60. Beique JC, Andrade R: PSD-95 regulates synaptic transmission and plasticity in rat cerebral cortex. J Physiol 2003, 546:859-867.

61. Calhoun ME, Jucker M, Martin LJ, Thinakaran G, Price DL, Mouton PR: Comparative evaluation of synaptophysin-based methods for quantification of synapses. J Neurocytol 1996, 25:821-828.

62. Chen X, Levy JM, Hou A, Winters C, Azzam R, Sousa AA, Leapman RD, Nicoll RA, Reese TS: PSD-95 family MAGUKs are essential for anchoring AMPA and NMDA receptor complexes at the postsynaptic density. Proc Natl Acad Sci U S A 2015, 112:E6983-6992.

63. Castellano $C$, Cestari V, Ciamei A: NMDA receptors and learning and memory processes. Curr Drug Targets 2001, 2:273-283.

64. Bear MF, Malenka RC: Synaptic plasticity: LTP and LTD. Curr Opin Neurobiol 1994, 4:389-399.

65. Dudek SM, Bear MF: Homosynaptic long-term depression in area CA1 of hippocampus and effects of N-methyl-D-aspartate receptor blockade. Proc Natl Acad Sci U S A 1992, 89:4363-4367.

66. Sans N, Prybylowski K, Petralia RS, Chang K, Wang YX, Racca C, Vicini S, Wenthold RJ: NMDA receptor trafficking through an interaction between PDZ proteins and the exocyst complex. Nat Cell Biol 2003, 5:520-530.

67. Losi G, Prybylowski K, Fu Z, Luo J, Wenthold RJ, Vicini S: PSD-95 regulates NMDA receptors in developing cerebellar granule neurons of the rat. J Physiol 2003, 548:21-29.

68. Kornau HC, Schenker LT, Kennedy MB, Seeburg PH: Domain interaction between NMDA receptor subunits and the postsynaptic density protein PSD-95. Science 1995, 269:1737-1740.

69. Lin Y, Skeberdis VA, Francesconi A, Bennett MV, Zukin RS: Postsynaptic density protein-95 regulates NMDA channel gating and surface expression. J Neurosci 2004, 24:10138-10148. 
70. Chapouthier G, Venault P: GABA-A receptor complex and memory processes. Curr Top Med Chem 2002, 2:841-851.

71. Yazaki-Sugiyama Y, Kang S, Cateau H, Fukai T, Hensch TK: Bidirectional plasticity in fast-spiking GABA circuits by visual experience. Nature 2009, 462:218-221.

72. Challis C, Boulden J, Veerakumar A, Espallergues J, Vassoler FM, Pierce RC, Beck SG, Berton O: Raphe GABAergic neurons mediate the acquisition of avoidance after social defeat. $J$ Neurosci 2013, 33:13978-13988, 13988a.

73. Milic M, Divljakovic J, Rallapalli S, van Linn ML, Timic T, Cook JM, Savic MM: The role of alpha1 and alpha5 subunit-containing GABAA receptors in motor impairment induced by benzodiazepines in rats. Behav Pharmacol 2012, 23:191-197.

74. Penzes $P$, Cahill ME, Jones KA, VanLeeuwen JE, Woolfrey KM: Dendritic spine pathology in neuropsychiatric disorders. Nat Neurosci 2011, 14:285-293.

75. Fritschy JM, Brunig I: Formation and plasticity of GABAergic synapses: physiological mechanisms and pathophysiological implications. Pharmacol Ther 2003, 98:299-323.

76. Prange O, Wong TP, Gerrow K, Wang YT, El-Husseini A: A balance between excitatory and inhibitory synapses is controlled by PSD-95 and neuroligin. Proc Natl Acad Sci U S A 2004, 101:13915-13920.

77. Gao R, Penzes P: Common mechanisms of excitatory and inhibitory imbalance in schizophrenia and autism spectrum disorders. Curr Mol Med 2015, 15:146-167.

78. Eichler SA, Meier JC: E-I balance and human diseases - from molecules to networking. Front Mol Neurosci 2008, 1:2.

79. Sohal VS, Zhang F, Yizhar O, Deisseroth K: Parvalbumin neurons and gamma rhythms enhance cortical circuit performance. Nature 2009, 459:698-702.

80. Xu X, Liu C, Li Z, Zhang T: Effects of Hydrogen Sulfide on Modulation of Theta-Gamma Coupling in Hippocampus in Vascular Dementia Rats. Brain Topogr 2015.

81. Li P, Rial D, Canas PM, Yoo JH, Li W, Zhou X, Wang Y, van Westen GJ, Payen MP, Augusto E, et al: Optogenetic activation of intracellular adenosine $A 2 A$ receptor signaling in the hippocampus is sufficient to trigger CREB phosphorylation and impair memory. Mol Psychiatry 2015, 20:1339-1349.

82. Pagnussat N, Almeida AS, Marques DM, Nunes F, Chenet GC, Botton PH, Mioranzza S, Loss $\mathrm{CM}$, Cunha RA, Porciuncula LO: Adenosine $\mathrm{A}(2 \mathrm{~A})$ receptors are necessary and sufficient to trigger memory impairment in adult mice. Br J Pharmacol 2015, 172:3831-3845.

83. Viana da Silva S, Haberl MG, Zhang P, Bethge P, Lemos C, Goncalves N, Gorlewicz A, Malezieux M, Goncalves FQ, Grosjean N, et al: Early synaptic deficits in the APP/PS1 mouse model of Alzheimer's disease involve neuronal adenosine A2A receptors. Nat Commun 2016, 7:11915. 
Figure legends

Fig.1 Photograph of the control, enriched environment and social isolation housing cage. a. Mice in CON group were housed in standard cages $(36 \times 18 \times 14 \mathrm{~cm})$ with 6 mice/cage. b. Mice in the EE group were raised in large $(60 \times 40 \times 35 \mathrm{~cm})$ with 6 mice/cage. and multilayer space and various toys such as houses, running wheels, hammocks, scales, small bells, ladders and tunnels. Objects were changed twice a week. c. Mice in the SI group were raised in standard cages with one mouse/cage without objects.

Fig.2 The effects of EE and SI on learning and memory. a. The experiment protocol of MWM test. b. Mean escape latency was determined for each day in MWM test among three groups. c. Mean swimming speed in MWM test. d. Mean percentage of time spent in target quadrant in the SET stage of MWM test. e. Mean number of platform area crossings in the SET stage of MWM test. f. Mean percentage of time spent in new target quadrant in the RET stage of MWM test. g. Mean number of platform area crossings in the RET stage of MWM test. h. The experiment protocol of NOR test. i. Recognition index in NOR test among three groups. j. Times of visit novel or old object in NOR test. k. Latency to novel object in NOR test. 1. Walking speed in NOR test. $* \mathrm{p}<0.05, * * \mathrm{p}<0.01$, compared with the CON group; \#\# $\mathrm{p}<$ $0.01, \# \# \#$ p $<0.001$, compared with the EE group, $n=6$ in each group.

Fig.3 The effect of EE and SI on the long-term potentiation and depotentiation from perforant pathway to dentate gyrus region in mice hippocampus. a. The 
timeline for electrophysiological recordings. The first 20 minutes of evoked responses were normalized and used as the baseline responses of LTP. The last 15 minutes of evoked responses during LTP were normalized and used as the baseline responses of depotentiation which was induced by low frequency stimulation (LFS). The inset shows an example of fEPSPs at baseline-TBS, LTP and depotentiation. b. The changes of time coursing in fEPSPs slopes in both LTP and depotentiation stages in the three groups. c. Magnitude of LTP was determined as responses between 40 and 60 minutes after the TBS. d. Magnitude of depotentiation was determined as responses between 40 and 60 minutes after LFS. Data are expressed as mean \pm SEM. $* \mathrm{p}<0.05, * * \mathrm{p}<0.01, * * * \mathrm{p}<0.001$, compared with the CON group; \#\# $\mathrm{p}<0.01$, \#\#\# $\mathrm{p}<0.001$, compared with the EE group, $\mathrm{n}=6$ in each group.

Fig.4 The effect of EE and SI on neural oscillations of mice hippocampus. a. The PLV between perforant pathway to dentate gyrus region in three groups. $b$. The mean phase synchronization strength under the environment of $n: m=3,4,5$ of three groups in PP alpha and LG. c. The weighted sum of phase synchronization strength of three groups in PP alpha and LG. d. The mean phase synchronization strength under the environment of $\mathrm{n}: \mathrm{m}=6,7,8,9$ of three groups in $\mathrm{PP}$ alpha and HG. e. The weighted sum of phase synchronization strength of three groups in PP alpha and HG. f. Representative PAC between PP alpha and DG gamma in three groups. Larger value indicates stronger coupling. g. the MI strength of PP alpha and DG gamma in three groups. Data are expressed as mean \pm SEM. $* \mathrm{p}<0.05, * * \mathrm{p}<0.01, * * * \mathrm{p}<$ 0.001, compared with the CON group; \# p $<0.05$, \#\# $\mathrm{p}<0.01$, \#\#\# $\mathrm{p}<0.001$, compared with the EE group, $\mathrm{n}=6$ in each group. 
Fig.5 The number of neurons and the level of synapse-associated proteins in tress groups. a. The representative optical microscope photographs of HE stained hippocampal DG region in tress groups. Scale bar: $100 \mu \mathrm{m}$. b. The density of DG cells in tress groups $(n=5)$. c. Results are immunoblots from single representative experiments of SYP and PSD-95. d. SYP/ $\beta$-actin band density ratio was measured in the three groups. e. PSD-95/ $\beta$-actin band density ratio was measured in the three groups. f. Representative images of PSD-95 density in DG and CA3 region. PSD-95 was stained with green, and nuclei were stained with blue. Scale bar: $20 \mu \mathrm{m} .{ }^{*} \mathrm{p}<$ $0.05, * * \mathrm{p}<0.01$, compared with the CON group; \#\# $\mathrm{p}<0.01$, compared with the EE group, $\mathrm{n}=3$ in each group.

Fig.6 Changes of excitatory/inhibitory synaptic density balance in three groups. a. Results are immunoblots from single representative experiments of NR2B, NR 2A and GABAAR. b. NR2B/ $\beta$-actin band density ratio was measured in the three groups. c. NR2A/ $\beta$-actin band density ratio was measured in the three groups. $d$. $\mathrm{GABA}_{\mathrm{A}} \mathrm{R} / \beta$-actin band density ratio was measured in the three groups. Data are expressed as mean \pm SEM. $* \mathrm{p}<0.05, * * \mathrm{p}<0.01$, compared with the CON group; \# $\mathrm{p}<0.05, \# \# \mathrm{p}<0.01$, compared with the EE group, $\mathrm{n}=3$ in each group. 


\section{Figures}

a

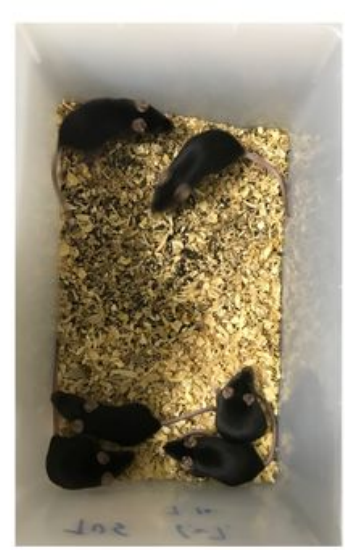

Control housing b

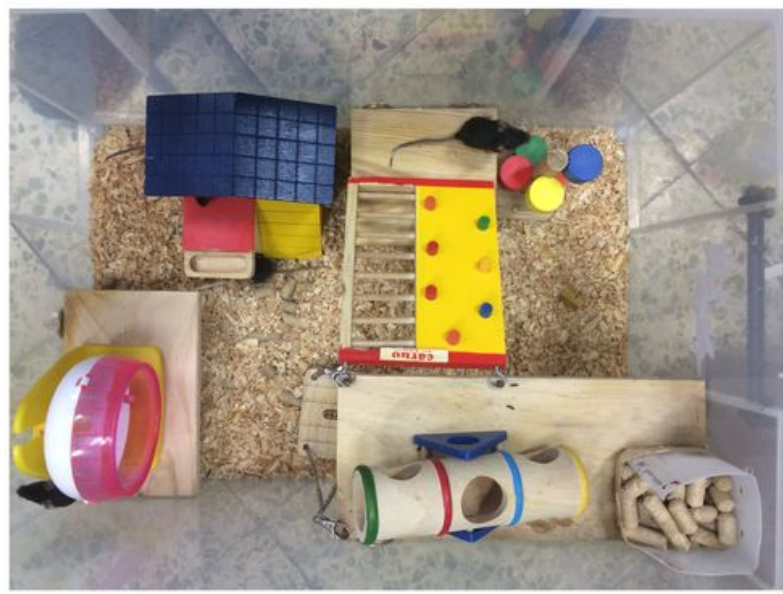

Enriched environment housing
C

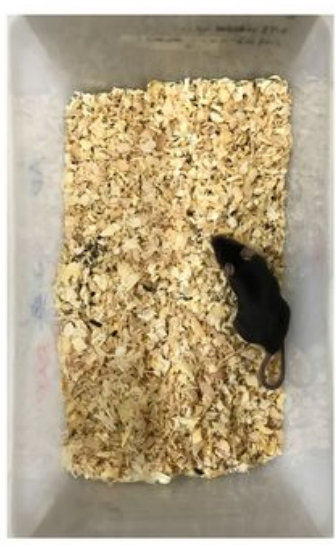

Social isolation housing

\section{Figure 1}

Photograph of the control, enriched environment and social isolation housing cage. a. Mice in CON group were housed in standard cages $(36 \times 18 \times 14 \mathrm{~cm})$ with 6 mice/cage. b. Mice in the EE group were raised in large $(60 \times 40 \times 35 \mathrm{~cm})$ with 6 mice/cage. and multilayer space and various toys such as houses, running wheels, hammocks, scales, small bells, ladders and tunnels. Objects were changed twice a week. c. Mice in the SI group were raised in standard cages with one mouse/cage without objects. 
a

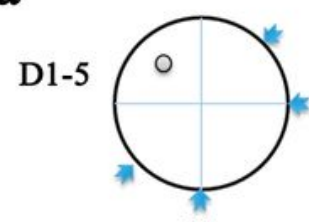

IT

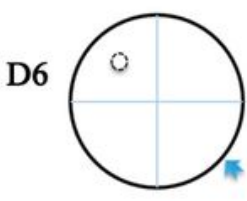

SET
D7-8

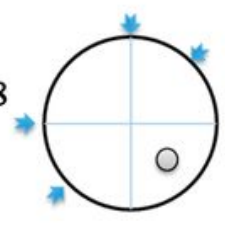

RT

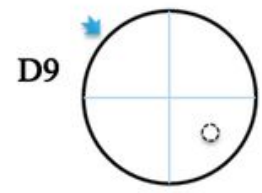

RET b
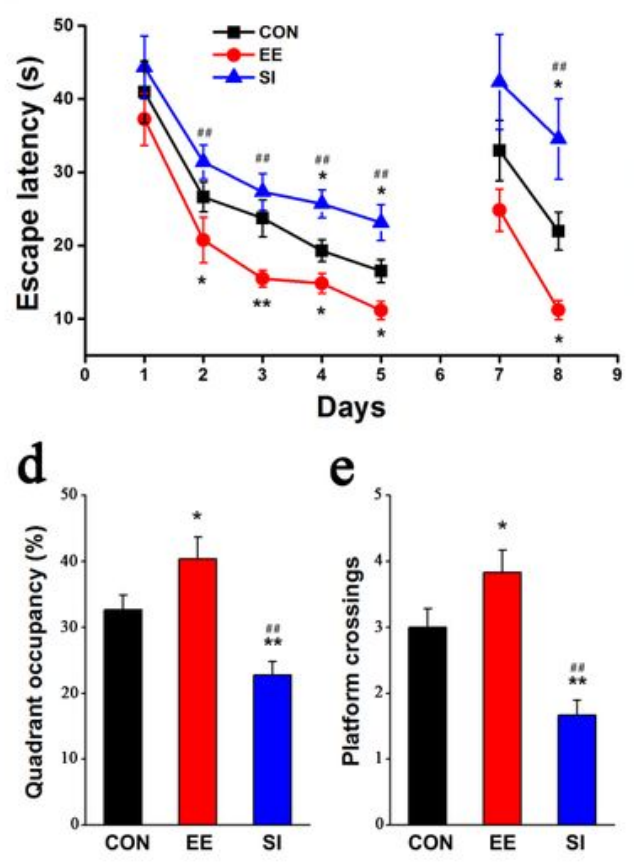

e

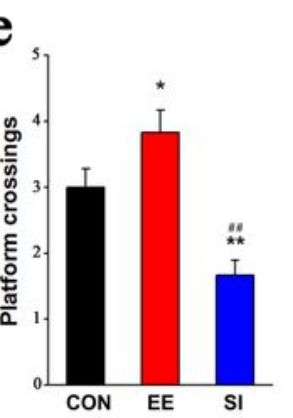

c
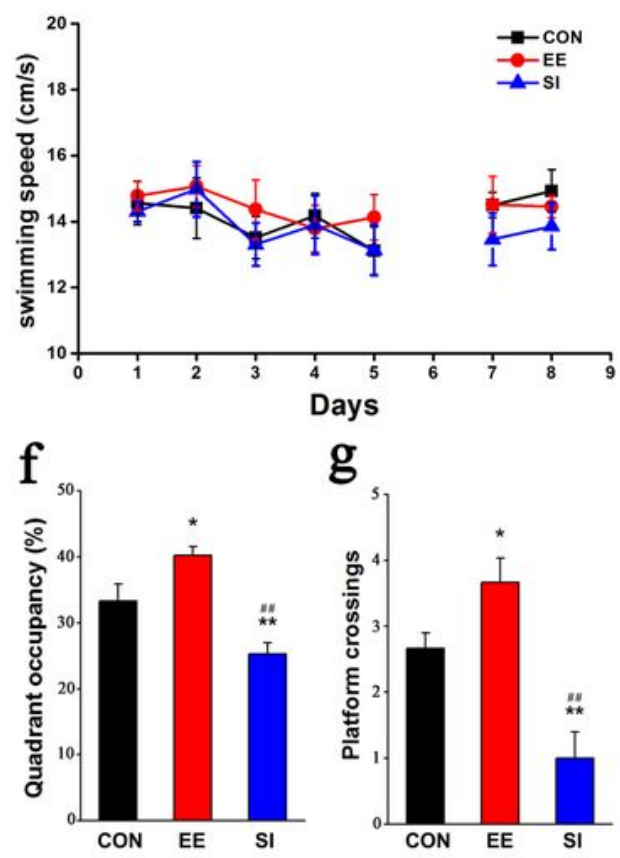

g

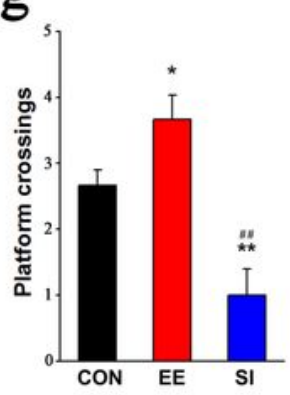

h

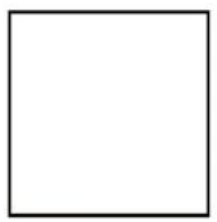

Habituation

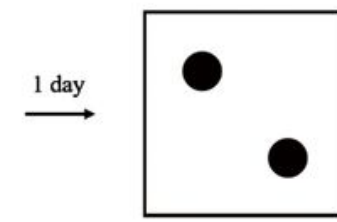

Training
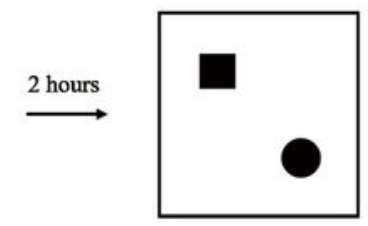

Testing
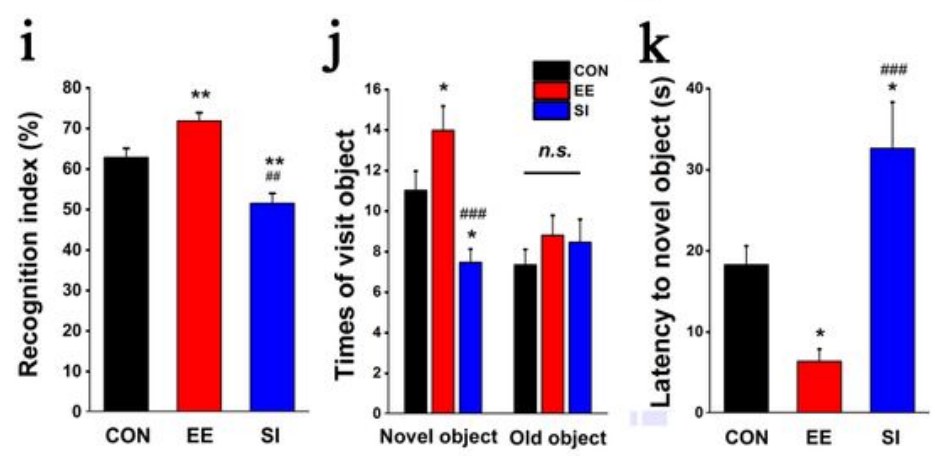

1

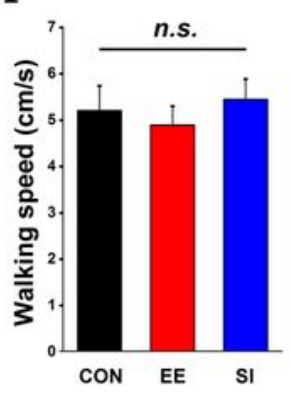

Figure 2

The effects of EE and SI on learning and memory. a. The experiment protocol of MWM test. b. Mean escape latency was determined for each day in MWM test among three groups. c. Mean swimming speed in MWM test. $d$. Mean percentage of time spent in target quadrant in the SET stage of MWM test. e. Mean number of platform area crossings in the SET stage of MWM test. $\mathrm{f}$. Mean percentage of time spent in new target quadrant in the RET stage of MWM test. $g$. Mean number of platform area crossings in the 
RET stage of MWM test. h. The experiment protocol of NOR test. i. Recognition index in NOR test among three groups. j. Times of visit novel or old object in NOR test. k. Latency to novel object in NOR test. I. Walking speed in NOR test. ${ }^{*} p<0.05$, ${ }^{\star *} p<0.01$, compared with the CON group; $\# \# p<0.01$, \#\#\#p< 0.001 , compared with the EE group, $\mathrm{n}=6$ in each group.

a

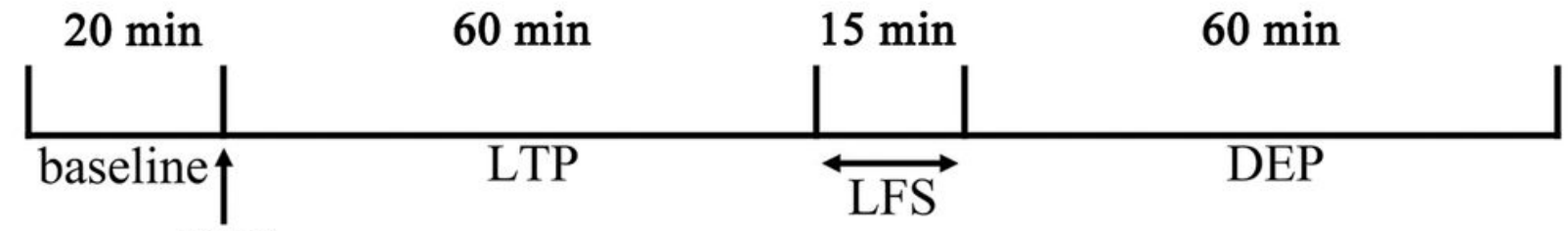

TBS

b
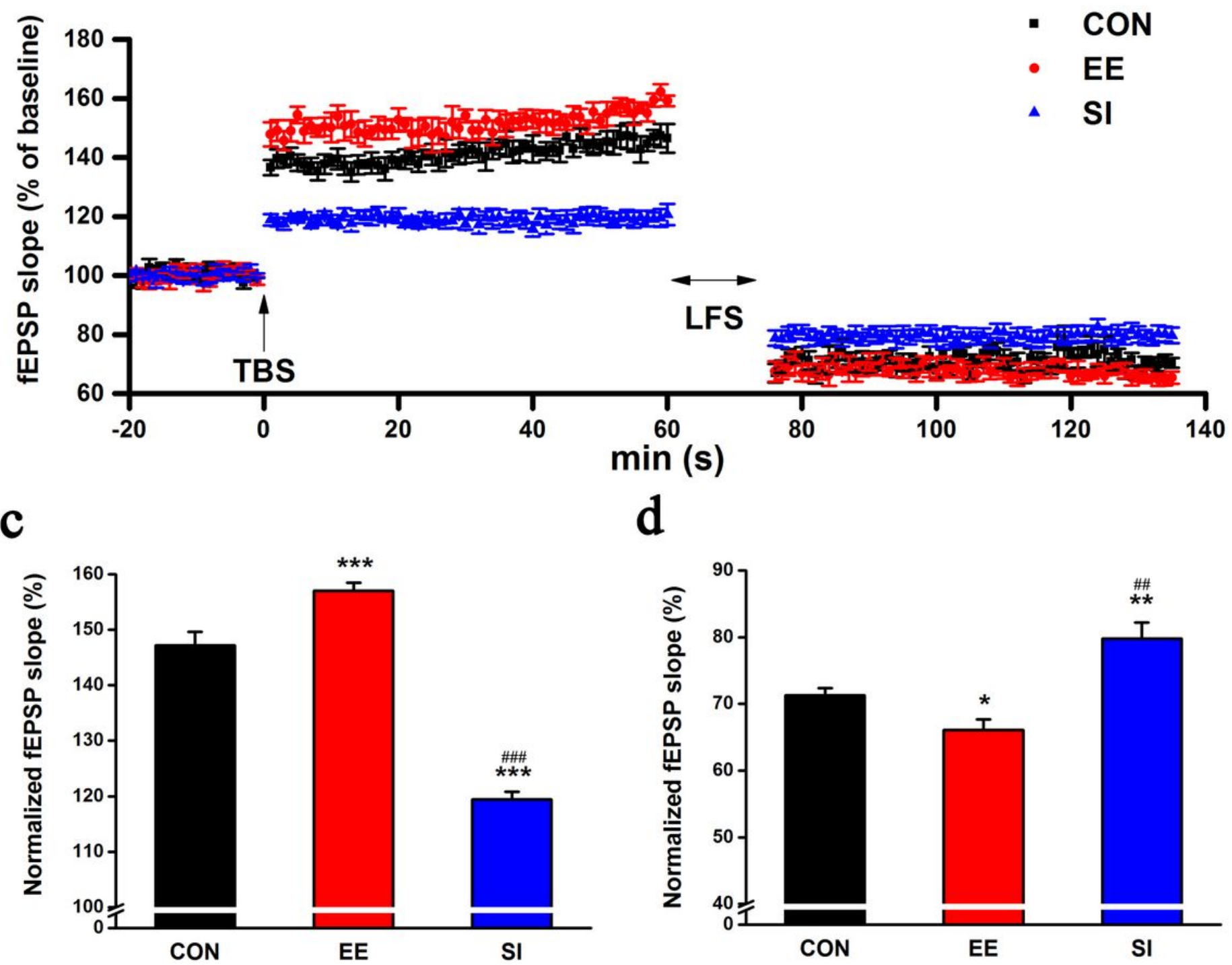

Figure 3

The effect of EE and SI on the long-term potentiation and depotentiation from perforant pathway to dentate gyrus region in mice hippocampus. a. The timeline for electrophysiological recordings. The first 
20 minutes of evoked responses were normalized and used as the baseline responses of LTP. The last 15 minutes of evoked responses during LTP were normalized and used as the baseline responses of depotentiation which was induced by low frequency stimulation (LFS). The inset shows an example of fEPSPs at baseline-TBS, LTP and depotentiation. b. The changes of time coursing in fEPSPs slopes in both LTP and depotentiation stages in the three groups. c. Magnitude of LTP was determined as responses between 40 and 60 minutes after the TBS. $d$. Magnitude of depotentiation was determined as responses between 40 and 60 minutes after LFS. Data are expressed as mean $\pm S E M$. * $p<0.05$, ${ }^{\star *} p<$

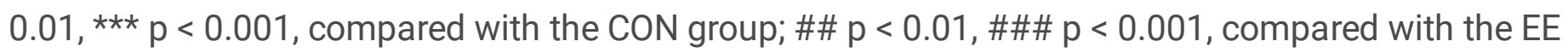
group, $\mathrm{n}=6$ in each group. 


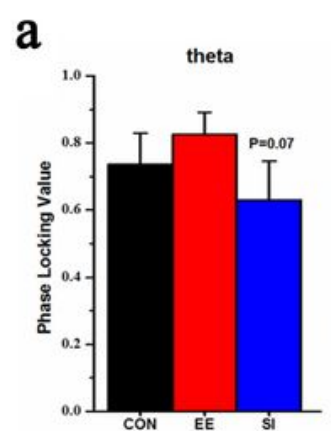

b

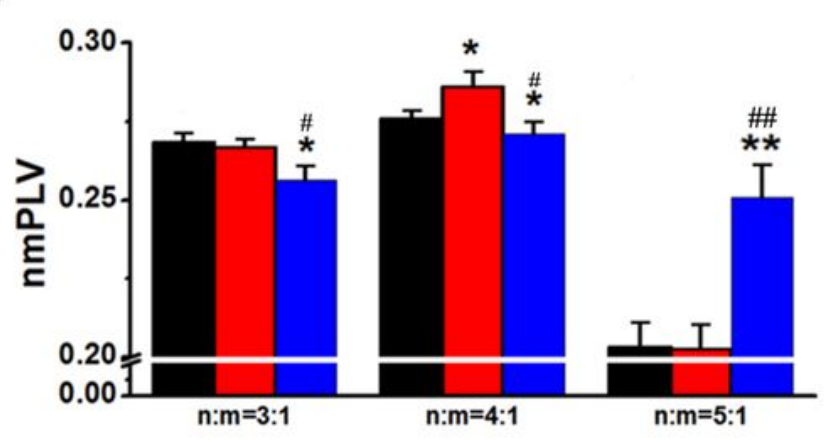

d

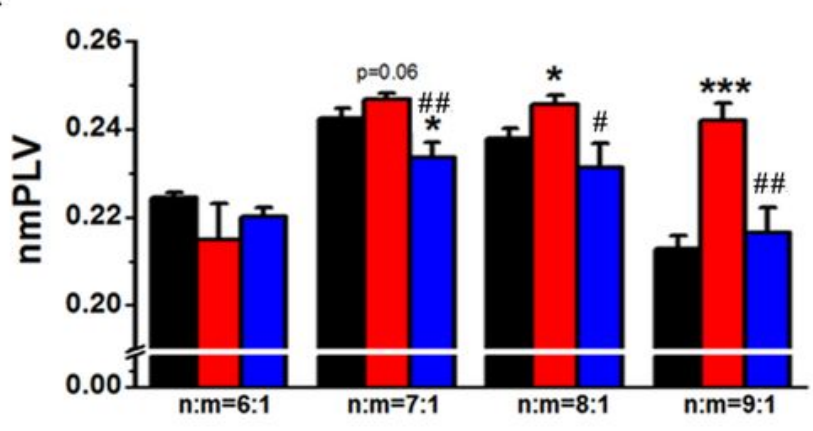

c
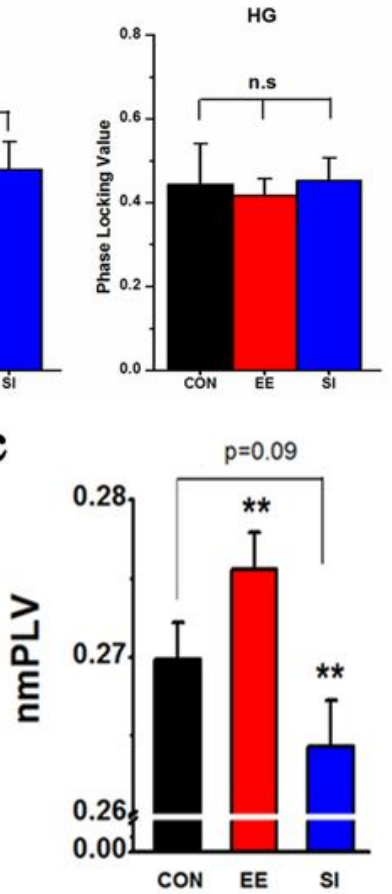

Co.

e

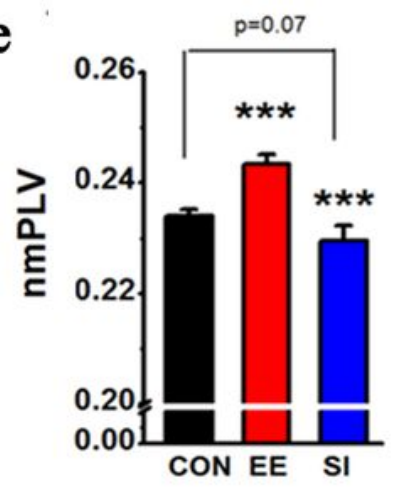

f

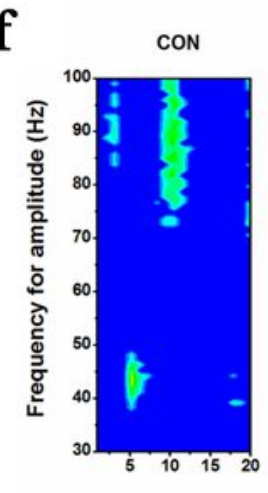

EE

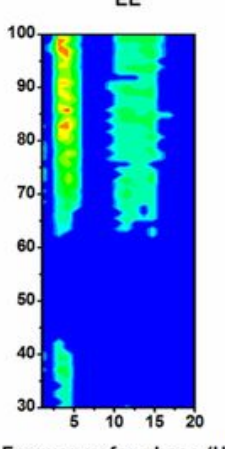

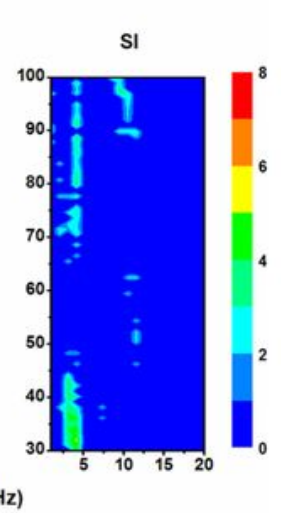

g

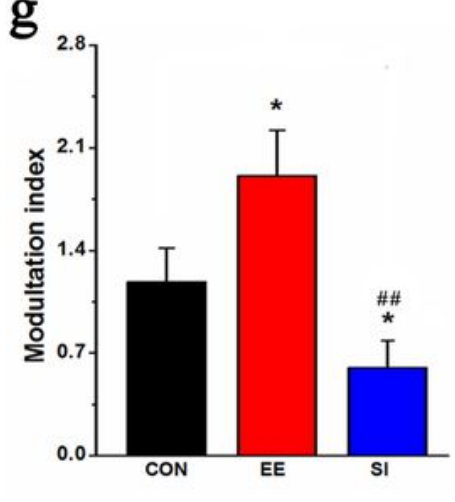

\section{Figure 4}

The effect of EE and SI on neural oscillations of mice hippocampus. a. The PLV between perforant pathway to dentate gyrus region in three groups. b. The mean phase synchronization strength under the environment of $n: m=3,4,5$ of three groups in PP alpha and LG. c. The weighted sum of phase synchronization strength of three groups in PP alpha and LG. d. The mean phase synchronization strength under the environment of $n: m=6,7,8,9$ of three groups in PP alpha and HG. e. The weighted sum 
of phase synchronization strength of three groups in PP alpha and HG. f. Representative PAC between PP alpha and DG gamma in three groups. Larger value indicates stronger coupling. g. the MI strength of PP alpha and DG gamma in three groups. Data are expressed as mean \pm SEM. ${ }^{\star} p<0.05,{ }^{\star \star} p<0.01$, $* \star \star ~ p<$ 0.001 , compared with the CON group; \# $p<0.05$, \#\# p $<0.01$, \#\#\# p $<0.001$, compared with the EE group, $\mathrm{n}=6$ in each group.

a

$\mathrm{CON}$
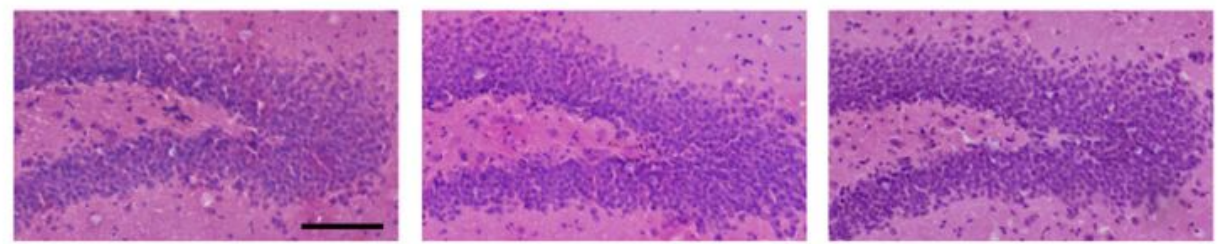

SI

C

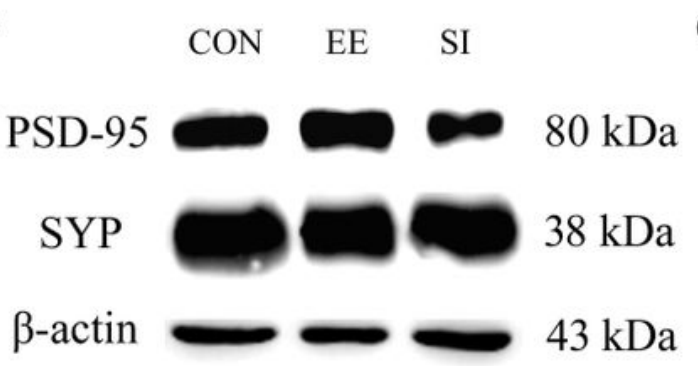

d

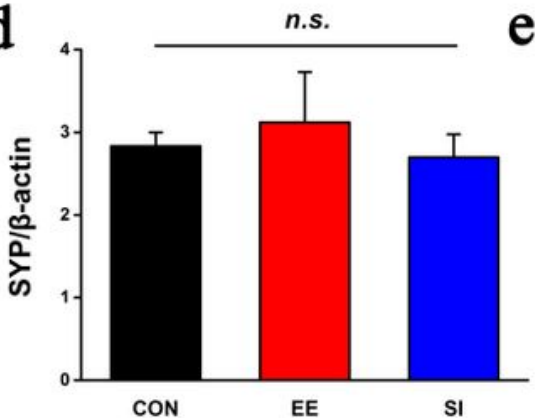

e
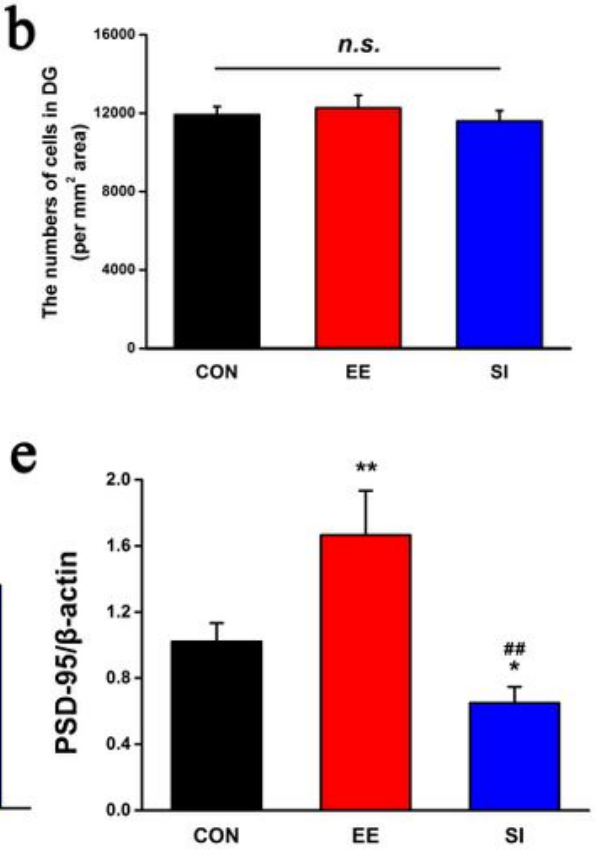

f

DG region

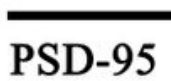

DAPI

Merge
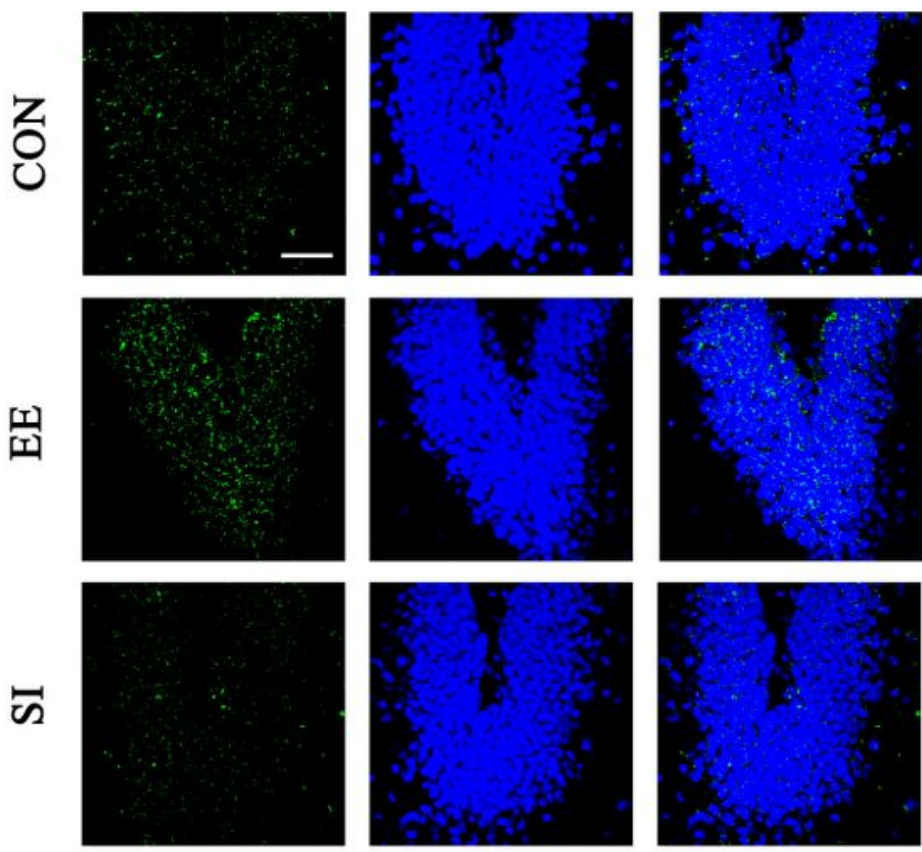

CA3 region

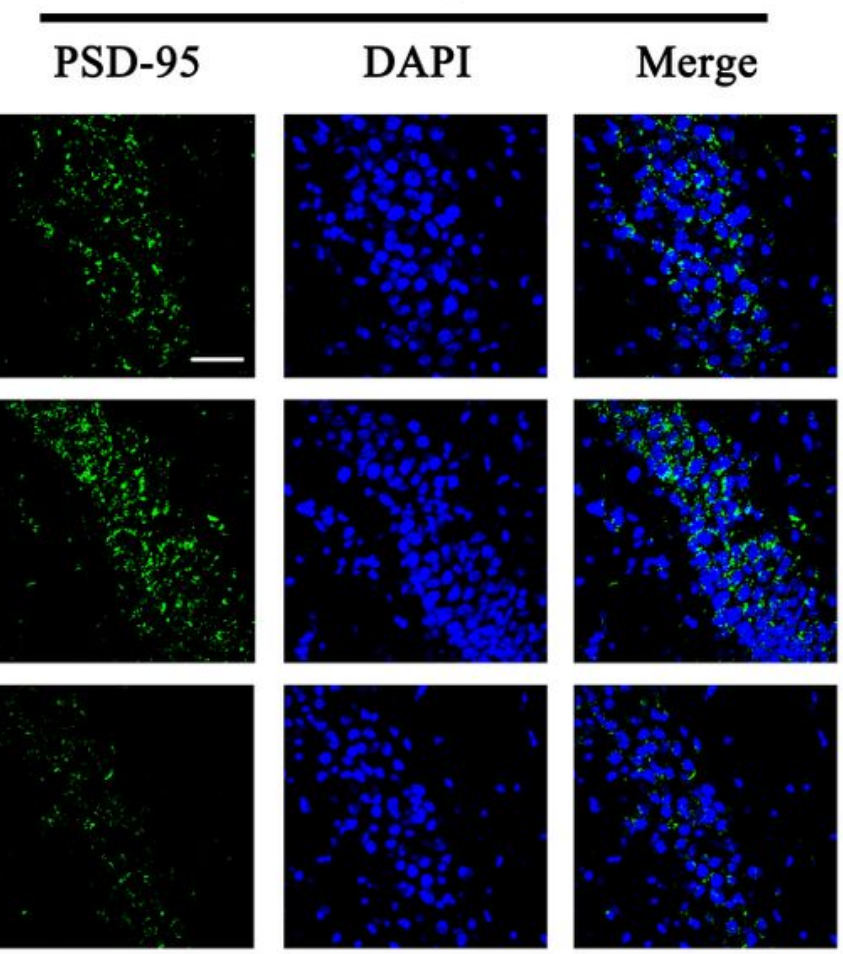

Figure 5 
The number of neurons and the level of synapse-associated proteins in tress groups. a. The representative optical microscope photographs of HE stained hippocampal DG region in tress groups. Scale bar: $100 \mu \mathrm{m}$. b. The density of DG cells in tress groups $(n=5)$. c. Results are immunoblots from single representative experiments of SYP and PSD-95. d. SYP/ $\beta$-actin band density ratio was measured in the three groups. e. PSD-95/ $\beta$-actin band density ratio was measured in the three groups. $f$.

Representative images of PSD-95 density in DG and CA3 region. PSD-95 was stained with green, and nuclei were stained with blue. Scale bar: $20 \mu \mathrm{m}$. ${ }^{*} p<0.05$, ${ }^{\star \star} p<0.01$, compared with the CON group; \#\# $p<0.01$, compared with the EE group, $n=3$ in each group.

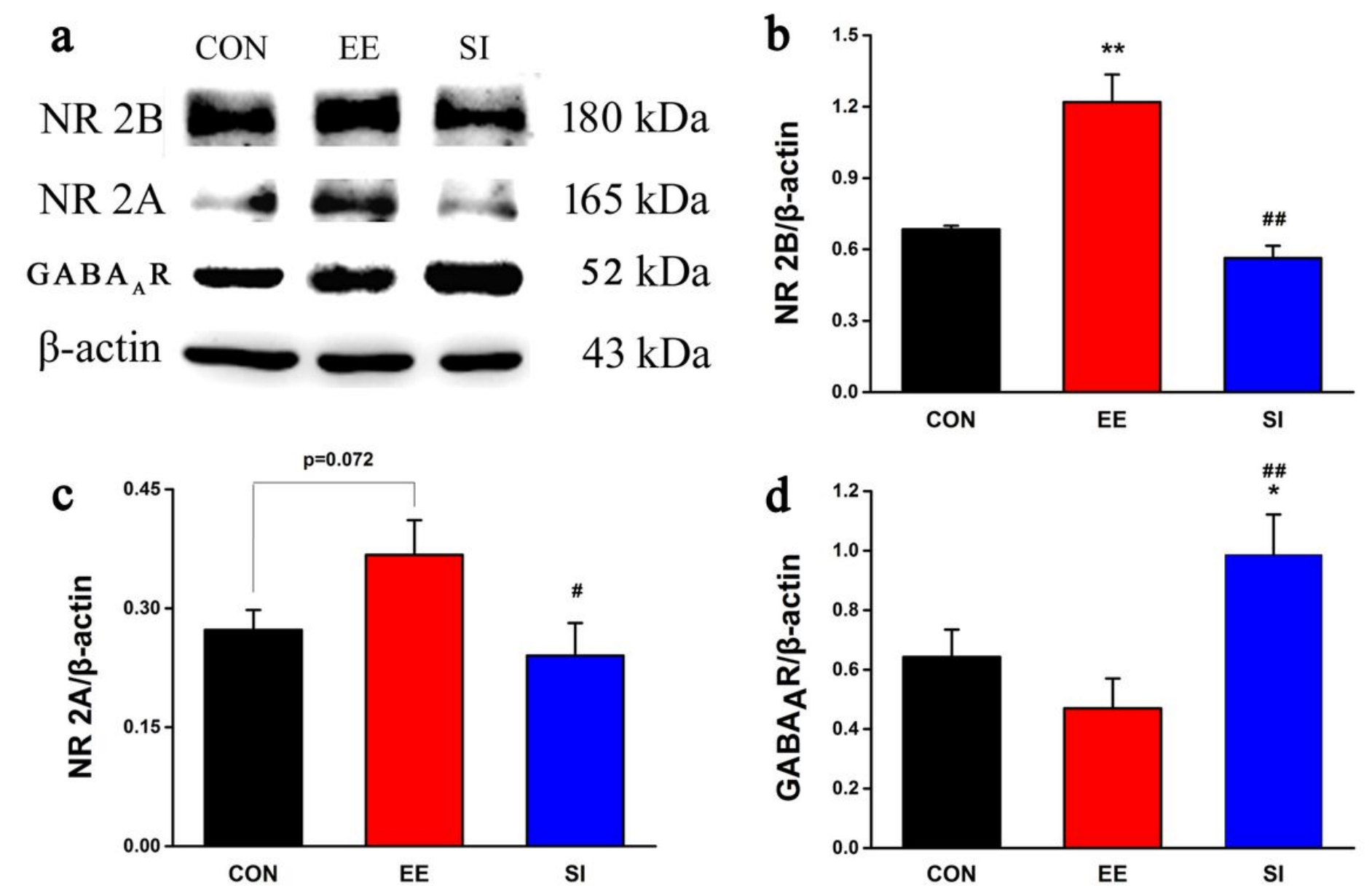

Figure 6

Changes of excitatory/inhibitory synaptic density balance in three groups. a. Results are immunoblots from single representative experiments of NR2B, NR 2A and GABAAR. b. NR2B/ $\beta$-actin band density ratio was measured in the three groups. $C$. NR2A/ $\beta$-actin band density ratio was measured in the three groups. d. GABAAR/ $\beta$-actin band density ratio was measured in the three groups. Data are expressed as mean \pm SEM. * $p<0.05$, ${ }^{* *} p<0.01$, compared with the CON group; $\# p<0.05$, \#\# $p<0.01$, compared with the EE group, $\mathrm{n}=3$ in each group.

\section{Supplementary Files}


This is a list of supplementary files associated with this preprint. Click to download.

- SupplementaryMaterials.docx 